SELF-REGULATORY STRATEGIES

\title{
Doing Despite Disliking: Self-Regulatory Strategies in Everyday Aversive Activities
}

Marie Hennecke, Thomas Czikmantori, and Veronika Brandstätter

University of Zurich

In Press at European Journal of Personality

\author{
Author Note \\ Marie Hennecke, Department of Psychology, University of Zurich, Switzerland; Thomas \\ Czikmantori, Department of Psychology, University of Zurich, Switzerland; Veronika \\ Brandstätter, Department of Psychology, University of Zurich, Switzerland. \\ Correspondence concerning this article should be addressed to Marie Hennecke, \\ University of Zurich, Department of Psychology, Binzmuehlestrasse 14/6, 8050 Zurich, \\ Switzerland. E-mail: m.hennecke@psychologie.uzh.ch \\ This research was supported by a research grant (\#100019_156516) from the Swiss \\ National Science Foundation awarded to Marie Hennecke and Veronika Brandstätter. \\ The authors would like to thank Corinne Kamm and Laura Tophinke for their help in \\ conducting the studies, Wilhelm Hofmann for his statistical advice, Benjamin A. Converse for his \\ comments on a first draft of this manuscript, the "Psychology of Motivation, Volition, and \\ Emotion” lab for their feedback on the work, and an anonymous reviewer for ideas on how to \\ make better use of our data. Unabridged study materials and reproducible scripts are publicly \\ available on the OSF (https://osf.io/vkd26/).
}


SELF-REGULATORY STRATEGIES

\section{Abstract}

We investigated the self-regulatory strategies people spontaneously use in their everyday lives to regulate their persistence during aversive activities. In pilot studies (pooled $N=794$ ), we identified self-regulatory strategies from self-reports and generated hypotheses about individual differences in trait self-control predicting their use. Next, deploying ambulatory assessment $(N=$ 264, 1940 reports of aversive/challenging activities), we investigated predictors of the strategies' self-reported use and effectiveness (trait self-control, demand types). The popularity of strategies varied across demands. In addition, people higher in trait self-control were more likely to focus on the positive consequences of a given activity, set goals, and use emotion regulation. Focusing on positive consequences, focusing on negative consequences (of not performing the activity), thinking of the near finish, and emotion regulation increased perceived self-regulatory success across demands, whereas distracting oneself from the aversive activity decreased it. None of these strategies, however, accounted for the beneficial effects of trait self-control on perceived self-regulatory success. Hence, trait self-control and strategy use appear to represent separate routes to good self-regulation. By considering trait- and process-approaches, these findings promote a more comprehensive understanding of self-regulatory success and failure during people’s daily attempts to regulate their persistence.

Keywords: self-regulation; self-control; strategies; persistence; goal pursuit 
SELF-REGULATORY STRATEGIES

Doing Despite Disliking: Self-Regulatory Strategies in Everyday Aversive Goal Pursuit In our daily lives, we sometimes need to engage in activities that we do not enjoy, often for the sake of a personal goal. Students, for example, may sometimes need to read textbooks they find profoundly boring, and athletes may need to practice their sports at painfully high intensities to increase their performance. Moreover, many occupations involve tasks that are perceived as monotonous (e.g., assembly line work) or require workers to cope with emotional stressors (e.g., in emergency management or intensive care units). When an activity is boring, difficult, or requires physical or mental effort, persistence in it requires self-regulation (or selfcontrol $)^{1}$, that is, processes by which individuals can alter their cognitive, emotional, or behavioral responses in the service of their long-term goals (Baumeister, Vohs, \& Tice, 2007).

To date, relatively little is known about how people try to promote their own persistence in such everyday activities. Which self-regulatory strategies do they spontaneously use? And how much do these strategies actually help them to persist? In the present research, we attempted to answer these questions while placing them into the larger context of individual differences in trait self-control. More specifically, we investigated (a) the self-regulatory strategies people use spontaneously in their everyday lives, for different activities and when confronted with various demands, (b) the reported effectiveness of these strategies as a function of demand types, and (c) the extent to which individual differences in trait self-control predict the use of self-regulatory strategies and (d) whether, in turn, the use of these self-regulatory strategies can explain why people, who are high in trait self-control, report being more successful in regulating their persistence in a given moment. 
SELF-REGULATORY STRATEGIES

\section{Self-Regulatory Strategies}

We understand self-regulatory strategies as the means through which individuals, in order to help themselves achieve their goals, actively alter their cognitive, motivational, affective, or behavioral reactions to a self-regulatory challenge. The goals may be long-term (e.g., losing 15 kilos) or short-term task goals (working off 300 calories on a treadmill). The challenges may be initiation-related (getting up from one's couch to go to the gym even if it is aversive), inhibitionrelated (not eating delicious chocolate cake) or persistence-related (staying on the treadmill even if it is aversive) (see Hoyle \& Davisson, 2016 for an introduction into the distinction of the three types of challenges). In the current research, we focus on the latter type of self-regulatory challenge, when the challenge lies in staying persistent in an aversive activity.

The strategies that people may use can capitalize on cognitive, motivational, affective, or behavioral processes. For example, a runner on a treadmill may use a cognitive strategy by imagining that she is not in a bland gym environment, but running in a race against the other people working out next to her. Using a motivational strategy, the runner may monitor her own progress with regard to her training goals by checking the distance she has already tackled. Using an affective strategy, the runner may try to improve her mood by thinking happy thoughts when the workout gets really hard and painful. Finally, using a behavioral strategy, the runner may decide to leave the gym and instead run in the more pleasurable environment of a nearby forest. Note, that these categories are intertwined. For example, the cognitive strategy of monitoring one’s progress may be effective through its effects on motivation which themselves may have been set off by the affective consequences of perceiving one’s progress as too slow (Carver \& Scheier, 1990).

Prior research has usually taken a relatively narrow focus on self-regulation strategies: A lot of work has focused on the effects of single strategies like implementation intentions 
SELF-REGULATORY STRATEGIES

(Gollwitzer, 1999), self-reinforcement (Bandura, 1976), goal setting (Locke \& Latham, 2002; 2006), or monitoring one’s goal progress (for a review, see Harkin et al., 2016), and either instructed participants to apply the strategy (e.g., Duckworth, White, Matteucci, Shearer, \& Gross, 2016b; Gollwitzer \& Brandstätter, 1997) or assessed its spontaneous deployment by the participant (e.g., Brickell, \& Chatzisarantis, 2007). Other work has not necessarily focused on a single strategy but on a specific context in which self-regulatory demands arise, like coping with boredom (Nett, Goetz, \& Hall, 2011; Sansone, Weir, Harpster, \& Morgan, 1992), self-regulated learning (e.g., Boekaerts, 1997; Dörrenbächer \& Perels, 2016; Pintrich \& De Groot, 1990; Zimmerman, 1990), academic writing (e.g., Zimmerman \& Risemberg, 1997), sports training (e.g., Green-Demers, Pelletier, Stewart, \& Gushue, 1998), or musical instrument practice (e.g., Nielsen, 2004). In the current work, we neither restrict our focus to single strategies, nor to specific self-regulatory demands. Rather we investigate a wide range of strategies for a wide range of self-regulatory demands, including mentally effortful, physically effortful, boring, and emotionally challenging tasks. To our knowledge, this is the first work to investigate the frequency of the spontaneous use of a large number of self-regulatory strategies in everyday (aversive or challenging) activities.

Despite the diversity of cognitive, motivational, affective, and behavioral processes involved in self-regulation, all (consciously used) self-regulatory strategies have in common that their use is, among other influences, probably a result of the person's metacognitive judgment that the activity at hand is aversive or challenging but that one should persist in it and that deploying a strategy may make persistence more likely (Mischel \& Mischel, 1983; Schunk \& Zimmerman, 1994). Which specific strategies are deployed then, probably reflects the person’s beliefs about what constitutes an effective strategy in a given situation (Courneya, \& McAuley, 1991; Kennedy \& Miller, 1976; Palmer \& Goetz, 1988). These beliefs probably result from past 
SELF-REGULATORY STRATEGIES

experiences and may, hence, represent helpful metacognitive knowledge (Mischel, 1981). They may, however, like all subjective beliefs, be misguided (e.g., Boggiano, Barrett, Weiher, McClelland, \& Lusk, 1987; Yeager \& Dweck, 2012). Accordingly, we expect that, overall, not all the strategies that individuals report using will actually promote persistence. It is probable, however, that individuals who are high in trait self-control tend to use those strategies that actually increase their persistence in a given activity.

\section{Strategies in the light of the process model of self-regulation}

Strategies cannot only capitalize on a variety of cognitive, motivational, affective, and behavioral processes, but they can also be deployed at various points in time. This is a central assumption of Gross’ modal model of emotion regulation (Gross, 1998a, 1998b), which was recently adapted to self-regulation as the process model of self-regulation (Duckworth, Gendler, \& Gross, 2016a; Duckworth, White, Matteucci, Shearer, \& Gross, 2016b). Based on the process model of self-regulation model, strategies can be organized along a regulatory sequence or cycle: It begins with the psychologically relevant situation, here: the activity for which persistence may have to be regulated. When pursuing a goal, individuals may, for example, deploy strategies related to situation selection by choosing a goal-related activity that they consider pleasant rather than one that they consider unpleasant and for which they would have to regulate their persistence (Woolley \& Fishbach, 2015). This could imply, for example, choosing running over the personally more dreadful rowing. Once selected, the activity or the situation in which it is performed may be modified to regulate persistence (situation modification). A person may, for example, add a second, more pleasant activity to accompany the unpleasant target activity, e.g., by listening to music while running on the treadmill (e.g., Butler, 1998). Next in the sequence, is the deployment of attention in the service of persistence regulation. Here, individuals may, for example, distract themselves from the unpleasant activity, for example by thinking about what to 
SELF-REGULATORY STRATEGIES

cook for dinner instead of focusing on their strained muscles. Cognitive change then refers to regulations of one's thoughts about and appraisals of the activity. For example, a person may try to think of the activity in light of its positive consequences as opposed to the effort it involves. Finally, response modulation involves altering one's response to the unpleasant situation, typically, by suppressing the impulse to quit and "just doing it."

\section{Strategy use as a process through which trait self-control "gets outside the skin?”}

Trait theories assume that people differ reliably from one another. Personality traits describe these individual differences in terms of characteristic thoughts, feelings, and behaviors (Funder, 2001). Individual differences in self-regulatory ability can be captured by assessing a person’s self-control, his or her “control over thoughts, emotional control, impulse control, performance regulation, and habit breaking” (Tangney, Baumeister, \& Boone, 2004, p. 282). Self-control is also a facet of conscientiousness (e.g., Goldberg, 1999), the Big Five personality trait that is the "most clearly relevant for self-regulation” (Hoyle, 2006, p. 1510). Like conscientiousness (see, for example Barrick \& Mount, 1991; Donnellan, Conger \& Bryant 2004; Ozer \& Benet-Martinez, 2006; Roberts, Kuncel, Shiner, Caspi \& Goldberg, 2007), trait selfcontrol is predictive of numerous real-life outcomes like better school performance, healthier behavior, and better socio-emotional adjustment (De Ridder, Lensvelt-Mulders, Finkenauer, Stok, \& Baumeister, 2012; Tangney et al., 2004). While it is among the most extensively studied traits to indicate individual differences in self-regulation or self-control and its beneficial consequences are well-known, little is known about how these individual differences "get outside the skin” (Hampson, 2012). Recent evidence suggest that self-control relates to a broad range of behaviors and processes beyond the effortful inhibition of undesired responses: For example, it has been associated with the proactive avoidance of temptation (Ent, Baumeister, \& Tice, 2015), the establishment of beneficial habits (Adriaanse, Kroese, Gillebaart, \& De Ridder, 2014; Galla 
SELF-REGULATORY STRATEGIES

\& Duckworth, 2015), the experience of one’s daily activities as more autonomously regulated (e.g., more fun and interesting; Converse, Juarez, \& Hennecke, 2018), and a weakened desire for temptations that conflict with a current goal (Hofmann, Baumeister, Förster, \& Vohs, 2012). We locate our approach within this broad view of trait self-control as reflecting a group of processes that determine how people pursue goals in different situations (Fleeson \& Jayawickreme, 2015; McCabe \& Fleeson, 2016). Strategy use may represent another process through which individuals high in trait self-control achieve their goals. According to this view, trait self-control represents a density distribution of momentary self-control enactment over time (Fleeson, 2001), that is aided by the use of strategies.

\section{The Present Research}

In the present research, we investigated the following research questions: (a) What are the self-regulatory strategies people spontaneously use in their everyday lives, when confronted with various demands (physical effort, mental effort, emotional challenge, boredom)? (b) As how effective do people experience these strategies in daily life and does their perceived effectiveness vary as a function of demand types? (c) Do individual differences in trait self-control predict the use of self-regulatory strategies? Do individuals high in trait self-control use strategies that appear as helpful to their self-regulation more often and strategies that appear as harmful to their self-regulation less often than individuals low in trait self-control? (d) And does their use of certain strategies in turn, explain why individuals who are high in trait self-control, report being more successful in self-regulating their persistence in a given moment?

In preparation of our confirmatory Main Study, we first ran three exploratory pilot studies (Pilot Studies 1, 2a, and 2b). The goal of Pilot Study 1 was to develop, in a bottom-up fashion, a list of self-regulatory strategies that people report using in their everyday lives to help themselves persist in unpleasant or challenging activities. Pilot Studies 2a and $2 \mathrm{~b}$ then explored associations 
SELF-REGULATORY STRATEGIES

between trait self-control and these strategies. We then attempted to replicate associations between trait self-control and the strategies in the Main Study, given they were already present in Studies 2a and 2b. Additionally, the Main Study served to test whether strategy use predicted self-regulatory success. It also allowed us to explore a number of interesting questions about the role of demands in determining strategy use and the association of strategy use and successful persistence. It furthermore tested the conceptual process model that individuals with high levels of trait self-control are more successful in regulating persistence in their goal pursuit, because they use more helpful and less harmful self-regulatory strategies. By testing this model, we also respond to a call for personality science to be less descriptive and more explanatory (Cramer et al., 2012; Fleeson \& Jayawickreme, 2015; Hampson, 2012) and to focus not only on the "what" of personality, but also on the "how" (Revelle, 1995).

To investigate how people deal with self-regulatory challenges in their daily goal pursuits, the Main Study deployed the method of ecological momentary assessment. This method allows researchers to understand people’s thoughts, feelings, and behaviors in their everyday lives by surveying them multiple times throughout a day over the course of several days (Csikszentmihalyi \& Larsen, 1987). Recently, self-regulation researchers have become interested in studying self-regulation through the use of this method (Friese \& Hofmann, 2016; Hofmann et al., 2012; Milyavskaya \& Inzlicht, 2017; Milyavskaya, Inzlicht, Hope, \& Koestner, 2015). So far however, this research has focused exclusively on self-regulatory conflicts that involve desires and temptations, while neglecting the kind of self-regulatory conflicts that are in the focus of the current work, namely when individuals try to persist in an aversive or challenging activity.

We determined our sample sizes before running our studies and we did not augment our samples after data analysis. We furthermore report all manipulations, and, in the unabridged materials that are publicly available on the Open Science Framework (goo.gl/jB99kY), all 
SELF-REGULATORY STRATEGIES

measures. Reproducible analysis scripts can also be found under this link. Unfortunately, we are unable to make the data public, as our informed consents at the time of data collection did not inform participants about this possibility. Hypotheses were not preregistered. The data are available upon request.

\section{Pilot Study 1}

To obtain a list of possible self-regulatory strategies used in everyday life in a bottom-up way, we asked participants to list strategies that they use to "keep themselves going” when they experienced a goal-directed activity as unpleasant or challenging. After coding participants’ responded, we checked, complementing the bottom-up approach with a top-down approach, whether the list of strategies we derived matched the strategies discussed most prominently in the self-regulation literature. This was the case (see Table 1 for an overview of strategies and their descriptions and Table S1 in the SOM for more information, including exemplary references).

[Insert Table 1 here]

\section{Method}

Sample. We had no prior expectations about what would represent a large-enough sample size. We expected that when advertising 330 hits on Mturk, we would get at least 100 participants with useful responses in each of three scenarios described below. We therefore opened up the study for 330 hits on Mturk. Mturk returned 335 participants, 6 of which did not provide any strategies and were therefore excluded. That left us with a final sample of $N=329$ participants (327 provided their age, 19-69 years, $M=35.7$ years, $S D=10.9$; 329 provided their gender, 44.1 $\%$ female). Mturk workers earned \$0.50 for their participation. All data were collected on October $15^{\text {th }}, 2015$.

Procedure. In order to capture the full range of self-regulatory strategies we decided to present each participant with one of three different scenarios, one implying a mentally 
SELF-REGULATORY STRATEGIES

challenging task (“exam” scenario), one implying a physically challenging task ("treadmill” scenario), and a third idiosyncratic variant (“idiosyncratic” scenario). The survey tool randomly assigned participants the different survey versions (see SOM). We decided to confront each participant with only one type of scenario because we worried that otherwise many participants could just name very similar strategies for each of the three scenarios to reduce the burden of consulting their own memory when having to consider different types of demands anyway. The “exam” scenario required participants to imagine themselves preparing for a difficult exam with boring materials. The "treadmill” scenario required participants to imagine themselves vigorously exercising on a treadmill. The "idiosyncratic" scenario required participants to name a rather frequent activity in their lives that they needed to perform to achieve a goal they considered important and that they did not enjoy at all. In all three scenarios, our target questions asked participants to write down strategies that they use to keep themselves going with these activities even if they are not enjoyable. We furthermore instructed participants that these strategies could include changing what they think about, attending to certain aspects of the situation, ignoring other aspects, changing what they feel, or changing what they do or how they do it. We did so to make sure that their responses would cover the regulatory processes proposed in Duckworth et al.’s (2016a) process model of self-regulation, which includes strategies of situation modification (“changing what they do or how they do it”), strategies of attentional deployment ("attending to certain aspects of the situation, ignoring other aspects”), strategies of cognitive change (“changing what they think about”), and strategies of response modulation (also "changing what they do”, although response modulation really includes “just doing it”, and hence not really using a specific strategy except for the use of one’s willpower, Duckworth et al., 2016b). Note, that while Duckworth's model also includes strategies of situation selection, we deemed those to not 
SELF-REGULATORY STRATEGIES

be relevant, because the situation in which persistence needed regulation had already been selected.

We then provided five empty entry boxes to which up to five more boxes were added one by one, if needed. With the goal to potentially explore participants' responses later, we afterwards asked a couple of additional questions depending on the scenarios (e.g., a question about how unpleasant they experienced preparing for exams in the past). These questions are not relevant to the current research agenda. Sociodemographic questions were the last procedural step.

\section{Results and Discussion}

Participants reported between 0 and 10 different self-regulatory strategies $(M=5.8, S D=$ 2.8), providing us with a total number of 1942 strategies. To combine these strategies into categories, we used a multiple-step coding approach. In the first step, the first author randomly pulled 100 strategies from participants’ responses across conditions in order to identify descriptive categories that most accurately and most parsimoniously corresponded to this subsample of strategies and that corresponded to strategies known from the self-regulation literature. She identified 25 distinct categories (including the categories "no strategy/nonsense response” and “other strategy”). Next, a research assistant with a Bachelor’s degree in Psychology used these 25 categories to code the same 100 strategies. There were 33 disagreements between the first author and the research assistant. Within the 67 agreements, four responses were unanimously identified as not meaningful. To increase future agreements, the coding system was improved, specifically by adding, for each strategy, a list of potentially similar but distinct other strategies from which coders should explicitly distinguish any strategy in question (see Table S1 in the SOM). The first author and two research assistants (both with Bachelor's degrees in Psychology) then independently coded a new random sample of 100 strategies. Agreement between these three coders ranged between 54\% and 71\%. After some 
SELF-REGULATORY STRATEGIES

additional clarifications within the coding system, another third random sample of 100 strategies was selected and independently coded by the two research assistants. Their agreement rate was $65 \%$, which corresponds to a Cohen's Kappa of .62, a score that is considered as "fair to good agreement beyond chance” (Fleiss, Levin, \& Paik, 1981, p. 604). Most importantly, none of the 300 coded strategies fell into the auxiliary category of "other strategy,” suggesting that the coding system was reliable and exhaustive. We therefore decided that we had attained our goal of extracting a comprehensive list of the kinds of strategies people use in their everyday lives. Without the categories "no strategy/nonsense response” and “other strategy”, the coding system contained 23 distinct strategies. These were, except for one, transformed into questionnaire items for subsequent studies. One strategy, focusing on consequences, was not transformed into its own item, as the two strategies focusing on positive consequences (of the activity) and focusing on negative consequences (of not performing the activity) already covered all possible thoughts of consequences, leaving us with 22 strategies. Of these 22 strategies, three did not refer to how people deal with wanting to persist with an unpleasant activity in the moment, namely taking a break, avoiding unpleasant activities altogether, and improving one's self-regulation outside of the activity (e.g., through reading self-help books). Accordingly, we do not consider these strategies further.

The 19 final strategies and the descriptions that allowed for their reliable assignment to categories are displayed in Table 1. Table $1 \mathrm{~S}$ in the supplemental online materials furthermore displays a (non-exhaustive) list of exemplary references to previous work that has already studied these or similar strategies. It is apparent that most of the strategies named by participants have already been discussed (albeit not together) in the basic or applied self-regulation literature. Most strategies could furthermore be organized along the sequential process model of self-regulation (see Figure 1, Gross, 1998a, 1998b; Duckworth et al., 2016a). Changing the activity itself, 
SELF-REGULATORY STRATEGIES

changing the environment, reducing distractions, seeking social support, taking a substance (e.g., coffee or an energy drink), and task enrichment (which implies adding something pleasant to the activity, like listening to music while exercising) can all be considered strategies of situation modification. They leave the target activity relatively intact but try to make persistence in it more likely by changing something about the conditions under which it is performed. Distracting oneself from the activity and adopting a process focus, which implies paying attention to the way one performs the activity, can be considered strategies of attentional deployment. These strategies include directing the focus of attention to features of the activity or outside of the activity to facilitate persistence. Cognitive change strategies, that is, strategies that help oneself to think differently about the activity included anticipating self-reward, focusing on negative consequences (of not performing the activity), focusing on positive consequences (of performing the activity), goal setting, monitoring one's goal progress, planning/scheduling, reappraisal, self-talk, and thinking of the near finish. Finally, one strategy clearly referred to response modulation, which entails voluntarily suppressing the impulse to quit.

In addition, one strategy was described that was not easily assigned to any of the four classes of strategies provided by the model. Some participants referred to emotion regulation without further specifying it (e.g., by describing that they were trying to stay in a good mood but not how). As emotion regulation can, as proposed in Gross’ model (e.g., Gross, 1998a, 1998b), be attempted along the entire sequence of situation selection, situation modification, attentional deployment, cognitive change, and response modulation, we could not assign it to any of these categories alone.

\section{[Insert Figure 1 here]}

It is important to note that we cannot guarantee having exhausted the full spectrum of all possible self-regulatory strategies in daily life. While we tried to elicit strategies for different 
SELF-REGULATORY STRATEGIES

kinds of activities and were successful in creating an exhaustive coding scheme, it is possible that some people may sometimes use other strategies that we have not yet covered. It is unlikely, however, that we missed other frequently used strategies with our approach. We will revisit this issue in the Main Study, where participants were able to report any other strategy that they may have used that was not on the list. If this were to be the case frequently, it would be necessary to revise our list of frequently used self-regulatory strategies.

After having obtained the list of self-regulatory strategies in this first Pilot Study, we wanted to test whether individual differences in trait self-control could predict the frequency of their usage in everyday life. For this reason and to decrease the number of hypotheses to be tested in the Main Study, we ran two more pilot studies (2a and $2 \mathrm{~b}$ ) to explore associations between trait self-control and strategy use. We expected that some of the strategies would show positive correlations with trait self-control, as their effectiveness is well-supported by prior research (e.g., goal setting, Locke \& Latham, 2002, 2006; or monitoring one’s goal progress, Harkin et al., 2016) and it is likely that individuals with high levels of self-control also use successful strategies. For some strategies, it was difficult to derive clear hypotheses. Take, for example, the strategy of focusing on the positive consequences of the activity: On the one hand, it has been shown that a focus on the desired outcomes or consequences of goal pursuit can be detrimental to persistence and success in goal pursuit (Fishbach \& Choi, 2012; Freund \& Hennecke, 2012, 2015). This makes it less likely that the strategy of focusing on the positive consequences of the activity is used by individuals with high self-control. On the other hand, goal activation (Fishbach, Friedman, \& Kruglanski, 2003; Shah \& Kruglanski, 2003) and motivation control (Kuhl, 1984) have both been discussed as potentially helpful in enabling persistence, and a promotion focus has been linked to higher trait self-control (Cheung, Gillebaart, Kroese, \& De Ridder, 2014). These findings, in turn, make it more likely that the strategy is used more by 
SELF-REGULATORY STRATEGIES

individuals with higher trait self-control. As we could not always derive clear hypotheses, we therefore decided to take a data-driven approach to hypothesis generation in the upcoming two pilot studies.

\section{Pilot Studies 2a and 2b}

As described earlier, we were interested in whether individual differences in self-control were correlated with the extent to which participants used self-regulatory strategies. To obtain correlations of trait self-control with strategy use, we asked participants to indicate how frequently, in the past, they had used the 19 strategies obtained in Pilot Study 1. For internal replication, we ran the same study with two samples, one English-speaking sample that we recruited through Mturk (Pilot Study 2a) and one German-speaking sample (Pilot Study 2b).

\section{Method}

Sample A. To attain precise correlation estimates, we posted 250 hits for workers from Canada and the US on Mturk (Schönbrodt \& Perugini, 2013). Deleting responses from participants, who had not provided their IDs or had incorrectly responded to an instructed response item ("To help us monitor our data quality, please choose the response option in the middle (neither agree nor disagree).”), left us with a sample of $N=245$ participants (19-74 years, $M=36.4$ years, $S D=12.1,42.4 \%$ female, $55.5 \%$ male, $0.4 \%$ other, $1.6 \%$ did not indicate their gender). Participants received $\$ 4.00$ as compensation. All data were collected on April 19 ${ }^{\text {th }}, 2016$.

Sample B. Again, to attain precise correlation estimates (Schönbrodt \& Perugini, 2013), our goal was to recruit 250 German-speaking participants. However, we quit data collection after 2 months, when no more new responses rolled in. Participants were psychology students and individuals, who had participated in previous studies of our lab. For compensation, psychology students received course credit; other participants took part in a raffle to win a book voucher (\$10). Additionally, we donated, for each participant, \$2 to a charity organization. Deleting 
SELF-REGULATORY STRATEGIES

responses from participants, who had failed to correctly respond to an instructed response item, left us with a sample of $N=220$ participants (18-74 years, $M=30.2$ years, $S D=11.6 ; 73.2 \%$ female, 23.2\% male, 3.6\% did not indicate their gender). All data were collected between January $15^{\text {th }}$ and March $16^{\text {th }}, 2016$.

Measures. Descriptive information for all variables is displayed in Table 2.

[Insert Table 2 here]

Frequency of use of self-regulatory strategies. For each of the 19 self-regulatory strategies identified in Pilot Study 1, we created English and German items and asked participants to indicate on a scale from 1 (never) to 5 (all the time), how often they had used the strategy in the past (see Table 1 for the English items). Both the English and the German items were developed in parallel at the same time when preparing Pilot Studies 2a and 2b. The team of the three authors of this manuscript, who are all fluent in both languages, formulated the items together and made sure that wordings in the two languages matched well with each other. The instructions introducing these items were as follows: "Sometimes, in order to attain a goal or avoid unpleasant consequences, we have to engage in activities that we experience as highly unpleasant, challenging, or boring. In such situations, we have to keep ourselves from stopping even though we feel like it. Some people, for example, find certain work tasks or exercising unpleasant, but nevertheless keep going. Please think of yourself in similar situations. Below you find a list of 22 strategies that people can use in order to keep going with an activity even when it is unpleasant. Please let us know how often you use such strategies and how effective you think these strategies are for you personally.” Note, that we still asked about 22 strategies but exclude the three strategies that did not refer to how people deal with wanting to persist with an unpleasant activity in the moment, namely taking a break, avoiding unpleasant activities altogether, and improving one's self-regulation outside of the activity (e.g., through reading self- 
SELF-REGULATORY STRATEGIES

help books) in our analyses. We also measured subjective effectiveness of the strategies, but because it was not the focus of this investigation, we do not report results here.

Trait self-control. In sample A, we measured trait self-control with the 13-item short version of the trait self-control scale (Tangney et al., 2004; $\alpha=.85$ ). A sample item is "I am able to work effectively towards long-term goals.” In sample B, we administered the German translation by Bertrams and Dickhäuser (2009) $(\alpha=.78)$.

\section{Results and Discussion}

Popularity of different self-regulatory strategies. Overall, average frequencies were very similar in the two samples, as indicated by a very high correlation of the average frequencies from both samples of $r(19)=.90,95 \%$ CI $[.76, .96], p<.001$. In sample A, participants reported that when being faced with an unpleasant or challenging task, they would most frequently focus on positive consequences, set goals, monitor their goal progress, think of the near finish, and use task enrichment to increase their persistence. In sample B, the strategy rewarding oneself was additionally among the five most popular strategies, whereas monitoring one's goal progress was somewhat less popular than in sample A. ${ }^{2}$

Trait self-control and strategy use. Next, we looked at whether a person's trait selfcontrol predicted how frequently that person uses a certain self-regulatory strategy. To be conservative in determining the strategies that were consistently related to trait self-control, we decided to only interpret correlations for strategies that correlated significantly with trait selfcontrol in both samples.

According to this criterion, seven strategies were positively and two strategies were negatively associated with trait self-control (see Table 2): People higher in trait self-control reported to more often reduce distractions, adopt a process focus, focus on the positive consequences of the activity, set goals, plan/schedule, reappraise the current activity, and 
SELF-REGULATORY STRATEGIES

regulate their emotions. They reported to less often distract themselves from the activity and focus on the negative consequences of not performing the activity.

With regard to the strategies that were positively associated with trait self-control, reducing distractions has already been deemed a very effective situation modification strategy (Duckworth et al., 2016b; Kuhl, 1984) while as of yet little was known about the extent to which individuals spontaneously deploy this strategy in their everyday lives (but see Wertenbroch, 1998).

As discussed before, for the strategy of focusing on the positive consequences of the current activity, the literature makes conflicting predictions. On the one hand, it is reflective of goal activation (Fishbach et al., 2003; Shah \& Kruglanski, 2003) and motivation control (Kuhl, 1984), which should have positive self-regulatory consequences. In addition, with its focus on positive outcomes of goal attainment (as opposed to negative outcomes of non-attainment), it indicates approach-motivated goal pursuit, which tends to be more productive than avoidancemotivated goal pursuit (e.g., Elliot, McGregor, \& Gable, 1999). On the other hand, a strong outcome focus has been found to have negative implications for persistence and goal attainment (Fishbach \& Choi, 2012; Freund \& Hennecke, 2012, 2015). Adopting a process focus, however, had positive implications for persistence and goal attainment in these studies (Freund \& Hennecke, 2012, 2015), a finding that is in line with the positive associations we found with selfregulatory traits in the current study. We will return to the question of whether and under which conditions focusing on the positive consequences of a goal helps or hurts self-regulation in the general discussion, after having established the strategies’ effects in the Main Study.

Many previous studies have demonstrated the positive self-regulatory consequences of setting goals and planning/scheduling (e.g., Gollwitzer \& Sheeran, 2006; Locke \& Latham, 2002). In an attempt to regulate their emotions during an unpleasant activity, people may focus 
SELF-REGULATORY STRATEGIES

on upregulating their positive affect or on downregulating their negative affect (Gross, 1998a, 1998b). The ability to regulate emotions is generally helpful for goal attainment (Hofmann, Friese, \& Roefs, 2009), and the strategy of reappraisal has been discussed as being especially helpful for self-regulation (e.g., Duckworth, Gendler, \& Gross, 2014; Fujita, 2011; Mischel \& Baker, 1975). Accordingly, the positive associations of the two strategies emotion regulation (not further specified) and reappraisal with trait self-control are in line with prior work attesting to their effectiveness.

The fact that distracting oneself from the activity correlated negatively with trait selfcontrol is noteworthy, as it was identified as a good strategy for coping with temptations in Mischel’s work (Mischel, Ebbesen, \& Raskoff Zeiss, 1972; Peake, Hebl \& Mischel, 2002; see also Duckworth et al., 2014). However, in the present study we asked about a different kind of self-regulation, namely persistence, and here distraction is aimed away from the unpleasant or challenging task. This may, in fact, draw attention to alternative activities outside of the focal unpleasant one and thereby reduce persistence.

Finally, focusing on the negative consequences of not performing the activity also correlated negatively with trait self-control. This suggests that high self-control goes hand in hand with an approach focus during the regulation of persistence but not an avoidance focus. This would be in line with prior research on avoidance motivation which has been shown to indeed be harmful to goal attainment (e.g., Elliot et al., 1999). It may be the case that negative cognitions that focus on threatening future prospects may disrupt current pursuits, for example, because they make the person prioritize the regulation of negative feelings over task completion. Individuals who do not adopt such a focus may, in turn, be more successful at self-control.

\section{Main Study}


SELF-REGULATORY STRATEGIES

While the previous studies were primarily exploratory in nature and served for generating our hypotheses, we next turned to a large-scale ambulatory assessment study for testing these hypotheses in the context of people's everyday activities. First, we aimed at confirming through replication that people who score high (vs. low) on the trait self-control more frequently reduce distractions, adopt a process focus, focus on the positive consequences of the activity, set goals, plan/schedule, reappraise the activity, and regulate their emotions (with no specification how); and that they less frequently distract themselves from the activity and focus on the negative consequences of not performing it.

Second, we aimed at testing whether strategy use was predicted by trait self-control. We also explored various types of demands as additional predictors of strategy use. Third, we aimed at testing whether using the strategies that were used more by people high in trait self-control were indeed more helpful for self-regulation, whereas the strategies that they used less were indeed more harmful for self-regulation, independent of specific demands. Finally, we aimed at testing whether strategy use could account for the supposedly positive effects of trait self-control on the regulation of persistence during aversive activities.

By deploying ambulatory assessment, we aimed at getting ecologically valid and relatively memory-bias free (Scollon, Prieto, \& Diener, 2009) information about (a) the frequencies, by which people face the self-regulatory demand of having to persist in an unpleasant or challenging task, (b) the frequencies by which they use each self-regulatory strategy to deal with such situations, and how these frequencies are contingent on demand types, and (c) the success of these regulatory efforts across a wide range of demands. Additionally, ambulatory assessment with its multiple measurement occasions for each participant allowed us to disaggregate between-person effects from within-person effects of strategy use (Curran \& Bauer, 2011; Hoffman \& Stawski, 2009). 
SELF-REGULATORY STRATEGIES

\section{Method}

Participants. Given the novelty of our research question and the difficulties involved in calculating sample sizes for studies with many repeated measures (e.g., Kreft \& De Leeuw, 1998; Scherbaum \& Ferreter, 2009), we based our recruitment goal on sample sizes in studies with similar designs and research questions (Friese \& Hofmann, 2016; Hofmann et al., 2012; Milyavskaya \& Inzlicht, 2017; Milyavskaya et al., 2015). ${ }^{3}$ In these studies final sample sizes varied between $N$ s of 101 and 205. We aimed at recruiting 200 participants with a minimum response rate of $70 \%$, so we over-recruited an original sample of 233 participants. In order to be enrolled in the study, participants had to own a smartphone with data service.

Due to technical problems, a number of participants did not receive the full number of signals, so, including other dropouts, 75 of these 233 (32.2\%) had a response rate below 70\%. Before having looked at the data, we therefore decided to augment the sample with a second wave of about 50 participants in the same semester. Data collection of both waves took four weeks in total, so we do not expect seasonal differences in any relevant variables between waves. Altogether the sample of these two waves was comprised of $N=287$ participants. Ultimately, due to technical problems or early dropout, 11 of these did not receive/respond to any signals and were therefore excluded from analyses. Another 12 participants did not report any episode where they had engaged in a somewhat unpleasant activity. Everyone who reported at least one episode where they had engaged in a somewhat unpleasant activity remained in the sample, leaving us with a final sample consisted of 264 participants (85\% female, 15\% male). Participants were between 18 and 54 years old $(M=23.0, S D=4.3)$. The majority held a high school $(74 \%)$ or university degree (23\%) and was enrolled in Psychology (70\%). Fifty-three percent of

participants were single, $44 \%$ in a relationship, $3 \%$ married, $2 \%$ had children. $41 \%$ reported being employed with an average work load of 30\% ( 12.6 hours per week, $S D=20 \%)$. On a scale from 
SELF-REGULATORY STRATEGIES

0 (very bad) to 10 (very good), the sample reported a high average language proficiency of $M=$ $9.4(S D=0.8)$. Fifty-one percent participated in exchange for course credit and $49 \%$ participated in exchange for financial reimbursement (up to \$70, contingent on completion). All data were collected between November $10^{\text {th }}$ and December $10^{\text {th }}, 2016$.

Procedure. Persons interested in participating were asked to go to a website that contained extensive information about the study procedure, data confidentiality, and compensation. By leaving their personal information on that website, they also provided informed consent to study participation. In a first e-mail after enrollment, participants received more detailed instructions on the study procedure, as well as web links to the two baseline surveys. Participants were asked to fill in these surveys within two days after receiving the email. Within these two days, we registered them for the study on SurveySignal ${ }^{\circledR}$, a web-based survey distribution and management provider (Hofmann \& Patel, 2015). Participants received, within one or two days, a validation text message, which also served to link their cell phone to a personal ID. On each of seven consecutive days, seven signals were distributed throughout a time window of 14 hours. Participants could, at the beginning of the study, decide whether they wanted to begin receiving the signals at 7am (24\%), 8am (33\%), 9am (29\%), or 10am (14\%). Consecutive signals were programmed to always be at least 1 hour apart and the link to the survey expired within 1 hour if a participant did not respond to it. If after 7 days participants had a response rate below $80 \%$, data collection was extended by 1 additional day (in $21 \%$ of cases). At the end of the study, the sample had an average response rate of $74 \%(S D=27 \%$; $M d n=$ $86 \%)$, and everyone in the sample had responded to at least two signals $(M=37.2, S D=13.0$, $M d n=43.0)$. The average response latency was $M=10.9$ minutes $(S D=14.5)$.

\section{Baseline.}


SELF-REGULATORY STRATEGIES

Trait self-control. As in Pilot Study 2b, we measured trait self-control with the 13 items from Bertrams and Dickhäuser’s (2009) German translation of Tangney et al.'s (2004) Short Trait Self-Control Scale (scales from $1=$ does not apply at all to $7=$ fully applies; $M=4.13, S D$ $=0.94$, actual range from 2.00 to $6.46, \alpha=.88$ ).

\section{Ambulatory assessment.}

Every signal led participants to the same survey that consisted of two parts: The first part will be described here; the second part is not relevant to the current investigation.

Activities with a self-regulatory challenge and demand types. At each measurement occasion, participants were asked whether, within the past hour, they had engaged in any activity that they experienced as unpleasant, challenging, or boring (response format: yes, I have/no, I have not). If participants had confirmed their engagement in such an activity, they were asked to assign it to one out of 23 activity type categories (e.g., participation in a study-related activity, e.g., lecture or seminar; self-instructed studying; work; meeting friends or acquaintances; housework) or, if it did not correspond to any of these categories, to describe the activity in their own words. Response categories were based on categories by Kahneman, Krueger, Schkade, Schwarz, and Stone (2004) and pretested with a different sample.

Next, participants were asked how unpleasant this activity had been for them overall on a scale from 1 (not unpleasant at all) to 7 (very unpleasant). We furthermore asked them to describe the activity's demands in more detail by indicating on seven items with scales ranging from 1 (not at all true) to 7 (very true), whether it was physically effortful $(M=2.22$, SD $=1.81)$; mentally effortful $(M=4.95, S D=1.85)$; too easy/monotonous $(M=3.55, S D=2.00)$; meaningless/superfluous $(M=2.89, S D=1.85)$; caused anger, sadness, disgust, or anxiety $(M=$ 2.63, $S D=2.00)$; was boring $(M=4.14, S D=2.10)$; or frustrating $(M=3.67, S D=1.99)$. These demand types were also pretested with a different sample to ensure that they covered most of the 
SELF-REGULATORY STRATEGIES

demands participants actually experience. ${ }^{4}$ Participants could also provide a free response to describe the reason why the activity was unpleasant (e.g., "took too much time,” "I was too tired," “it hurt”).

Self-regulatory strategies. Next, participants were asked to pick all strategies that they had used "to perform the activity, even though it was unpleasant" from the list of the 19 strategies (e.g., “I reduced or removed distractions and temptations.”). If participants had used a different strategy that was not part of the list, they could provide their own response to the question as well if they had used a different strategy (e.g., "I bought and ate some chocolate,” "I looked for a solution”). Participants could pick more than one strategy at a time. In fact, they reported having used between 0 and 13 strategies $(M=2.27, S D=1.82)$.

Perceived self-regulatory success. Finally, we asked participants about how satisfied they were with how long they had persisted in the activity on a scale from 1 (not satisfied at all) to 7 (absolutely satisfied) $(M=5.15, S D=1.59)$. We decided to frame our question like this to capture, in one item, participants’ experience of potential discrepancies (or the lack thereof) between their desired and their actual persistence, which we consider a good proxy for their momentary self-regulatory success (see Carver \& Scheier, 1990; Higgins, 1987; Michalos, 1985). Afterwards, the second part of the ambulatory assessment survey followed (see OSF-page).

Data Structure and Analysis. We collected data at two levels of measurement: An observation-level or Level 1 (measurement occasions), at which the ambulatory assessment data was located, and a person-level or Level 2, at which individual characteristics from the baseline measures, here: trait self-control, were located. Because observations were nested within persons, hypothesis tests were conducted using the "Ime4" package for multilevel modeling (Bates, Maechler, Bolker, \& Walker, 2015) in R (R Core Team, 2017) or, for the multilevel mediation models, using the software Mplus 7.31 (Muthén \& Muthén, 1998-2015). Note, that for each 
SELF-REGULATORY STRATEGIES

strategy, its use at any given occasion was assessed as a binary variable $(0=$ strategy was not used, 1 = strategy was used). Therefore, in the analyses predicting strategy use (except for the multilevel mediation models, see below), we applied logistic multilevel regression analyses provided by the "glmer" function.

To predict strategy use from people’s trait self-control, we followed a stepwise approach that allowed us to be conservative in our interpretations and to restrict the number of models to a minimum while also having enough power to detect associations. We only ran models for strategies (1) for which we had found consistent correlations with trait self-control in Pilot Studies 2a and 2b and (2) that had been used in at least $10 \%$ of all occasions in which participants had engaged in an unpleasant activity. The following strategies fulfilled both criteria: Distracting oneself from the activity, focusing on negative consequences, focusing on positive consequences, goal setting, and emotion regulation (not further specified). Accordingly, we aimed at replicating that, when regulating their persistence, people with higher trait self-control are more likely to focus on the positive consequences, set goals, and show emotion regulation (not further specified) and less likely to distract themselves from the activity and focus on the negative consequences (of not performing it) than people with lower trait self-control.

To test whether strategy use mediated the effects of trait self-control on self-regulatory success, we ran mediation models in Mplus that applied the robust weighted least squared estimator to predict strategy use, which was a binary variable for each strategy (referred to as WLSMV in Mplus; Muthén \& Muthén, 1998-2015).

As advised (Enders \& Tofighi, 2007), the person-level (or Level 2) predictor trait selfcontrol was grand-mean centered prior to analyses. Accordingly, intercepts can be interpreted as outcome scores for a person with an average level of trait self-control. All predictors on the level 
SELF-REGULATORY STRATEGIES

of measurement occasions (Level l) were group-mean centered (here: within participants) prior to analyses.

\section{Results and Discussion}

Descriptive findings. At 18.7\% (1940 in total) of all responded-to signals participants reported having engaged in an activity that was unpleasant or otherwise challenging to their selfregulation. The most frequently mentioned activity was "self-study” with 39\%, followed by "lecture/seminar” with 26.6\%, “commuting” with 11.5\%, "work” with 8.7\%, “other activities” with 7.8\%, “social contact per phone, internet, or through social networks” with 6\%, and "housework" with 5.5\%. All other types of activities were mentioned at less than 5\% of occasions. Note that in general, multiple mentions were allowed, and participants could, for example, report that they were both eating and commuting.

We also explored the general unpleasantness as well as the specific demands posed by the unpleasant activities based on the items that measured whether they were physically effortful; mentally effortful; too easy/monotonous; meaningless/superfluous; caused anger, sadness, disgust or anxiety; was boring; or frustrating. Based on high inter-item correlations (see Table S2 in the SOM), we built aggregate scores for boredom (average of “too easy/monotonous," "meaningless/ superfluous," and "boring”, $r$ s between these three items ranged from .40 to .69 , all $p s<.001, \alpha=$ .77) and for emotional challenge (average of “caused anger, sadness, disgust or anxiety” and “frustrating”, $r=.87, p<.001)$. The overall level of unpleasantness across activities was, as intended, rather high $(M=4.12, S D=1.46$, ICC $=.20)$. Across reported self-regulatory conflicts, participants most strongly experienced mental effort $(M=4.95, S D=1.85$, ICC $=.23)$, followed by boredom $(M=3.52, S D=1.64$, ICC $=.27)$, emotional challenges $(M=3.15, S D=1.74$, ICC $=$ $0.34)$, and lastly, physical effort $(M=2.22, S D=3.28$, ICC $=.19)$. As can be seen in Figure 2, there was a great amount of variety in these experiences across activities. The greatest 
SELF-REGULATORY STRATEGIES

unpleasantness was reported for “other activities” (e.g., "standing in line,” “correcting a friend’s thesis," "job interview," "participating in a research study”), followed by "housework.” The greatest physical effort and boredom was experienced during “housework,” the greatest mental effort during "self-study," and the greatest emotional challenge during "social contact per phone etc..”

[Insert Figure 2 here]

We checked whether trait self-control predicted how frequently participants reported having executed an unpleasant or challenging activity. This was not the case. We also checked whether trait self-control predicted the degree of overall unpleasantness $(M=4.13, S D=1.46)$. There was a tendency for participants with high trait self-control to experience activities as less unpleasant $(B=-0.15,95 \%$ CI [-0.26, -0.03], $p=.011)$, and, more specifically, as less emotionally challenging $(B=-0.29,95 \%$ CI $[-0.44,-0.13], p<.001)$ and less boring $(B=-0.25$, 95\% CI [-0.39, -0.12], $p<.001)$.

Overall popularity of different self-regulatory strategies. How frequently do people use the 19 strategies in their daily lives? As in the Pilot Studies 2a and 2b, participants most frequently reported having focused on positive consequences (used during $n=695$, that is in $36 \%$ of all unpleasant activities). Thinking of the near finish was the second most popular strategy ( $n=$ 535), followed by task enrichment ( $n=400)$, focusing on negative consequences $(n=325)$, suppressing the impulse to quit $(n=291)$, emotion regulation (not further specified) $(n=290)$, distracting oneself from the activity $(n=261)$, monitoring one's goal progress $(n=233)$, and goal setting $(n=194)$ (see Figure 3 for proportions). All other strategies were used in less than $10 \%$ of all measurement occasions. Generally, the relative frequencies by which strategies were used in the Main Study correlated highly with the average frequencies of strategy use from Study 
SELF-REGULATORY STRATEGIES

2a $(r(19)=.61,95 \%$ CI [.22, .83], $p=.005)$ and Study 2b $(r(19)=.65,95 \%$ CI $[.28, .85], p=$ $.003)$.

Note, that in only $2.2 \%$ of all measurements at which participants had reported strategy use, they indicated a strategy that was not on our list. This confirms that our list of 19 strategies covered the most frequently used self-regulatory strategies of daily life.

[Insert Figure 3 here]

Popularity of strategy use by demand type. Next, we explored which strategies were used as a function of the types of demands that participants had experienced. We ran a series of multilevel regression analyses (random intercept models only, as models with random slopes did not converge) predicting the use of each strategy by the reported intensity of the four types of demands (physical effort, mental effort, emotional challenge, and boredom; see Table 3). Note that whether $p$-values from exploratory analyses like these can be interpreted is currently being discussed (Nosek, Ebersole, DeHaven \& Mellor, 2017; Nosek \& Lakens, 2014; Forstmeier, Wagenmakers, \& Parker, 2016; see also Dahl, Grotle, Benth, \& Natvig, 2008; De Groot, 2014). However, as $p$-values are good predictors of replication success (Open Science Collaboration, 2015), and recent theorizing attests to their validity even in exploratory analyses (Rubin, 2017), we will use them as guides to highlight certain trends in the data.

The use of all strategies was predicted by demands, indicating that strategy popularity varies as a function of the way an activity is experienced (see Table 3). It was not the case that all types of demands just increased the likelihood that a strategy would be used. Rather, some types of demands actually decreased the likelihood that a given strategy would be used, presumably because these strategies were not perceived as effective or could not be used (e.g., due to the cognitive load already involved in the activity). Let us elaborate on a couple of interesting trends in the data. With higher levels of mental effort, participants were less likely to use task 
SELF-REGULATORY STRATEGIES

enrichment or to distract themselves from their activity. This suggests that when mental effort, and hence, cognitive load, is high already, people do not look for additional stimulation. Boredom, in turn, positively predicted task enrichment, and distraction, presumably because people were looking for additional stimulation (Hebb \& Thompson, 1954). Mental effort and boredom also appear different in the sense that mental effort evoked classical goal-related strategies of self-regulation like goal setting and monitoring, whereas boredom was even negatively related to goal setting. Physical effort predicted the lowest number of strategies, namely task enrichment, focusing on the positive consequences (both positively), and focusing on negative consequences (negatively). Finally, emotional demands did not increase the likelihood of use for any strategies but only made task enrichment, focusing on the positive consequences, goal setting, monitoring one's progress, and thinking of the near finish less likely.

[Insert Table 3 here]

Trait self-control and strategies. Does a person's level of trait self-control predict how frequently that person uses a certain self-regulatory strategy? As described above, we only ran models for strategies for which we had, in Studies 2a and 2b, found consistent correlations with trait self-control, and that participants had used in at least $10 \%$ of all occasions (see Figure 3 ) in which they had performed an unpleasant/challenging activity in the current study. Replicating the results from the two pilot studies, participants with higher trait self-control more frequently focused on positive consequences, set goals, and regulated their emotions. For easier interpretation of the log-odds displayed in Table 4, Figures 4 shows the predicted strategy use for people with average level of trait self-control and with levels that are $1 S D$ above or below the average.

[Insert Table 4 here]

[Insert Figure 4 here] 
SELF-REGULATORY STRATEGIES

Perceived self-regulatory success as a function of specific strategies. Next, we tested whether the ten self-regulatory strategies that were used in more than $10 \%$ of occasions in which participants had engaged in an unpleasant or challenging activity, were, according to participants’ self-reports, helpful in increasing participants’ success in regulating their persistence. As previously reported, strategy use was somewhat contingent of the kinds of demands participants had reported. Therefore, to de-confound the effects of strategy use and activity type/demands on subjective self-regulatory success, we simultaneously estimated the effects of demand types in a series of hierarchical linear models. We furthermore added interaction terms to these analyses to explore whether perceived strategy effectiveness varied as a function of demand types. All models (one for each strategy, all other predictors were entered simultaneously) included random effects for the intercept only, as models also including random slopes did not converge. We predicted that the three strategies, that were more frequently used by individuals with high levels of trait self-control (focusing on positive consequences, setting goals, emotion regulation [not further specified]) should also, across demands, be positively related to perceived self-regulatory success. Due to the large number of results, we have moved the respective tables to the SOM (see Tables S3 to S11) and report, in text, regression coefficients for significant associations only.

Across these models, there were consistent main effects of demands: Whereas physical effort positively predicted perceived self-regulatory success (effects ranging from $B=0.11$ to $B=$ 0.18 , all $p s<.001$ across models), emotional challenges (effects ranging from $B=-0.27$ to $B=$ 0.31 across models, all $p s<.001$ ), and boredom negatively predicted it (effects ranging $B=-0.12$ to $B=-0.20$ from to across models, all $p s<.001)$. There were no effects of mental effort on perceived success. It is possible that in our sample, which contained many students, there was a lot of pressure to even finish mentally effortful tasks, independent of how mentally effortful they were. The positive effect of physical effort on perceived self-regulatory success is surprising and 
SELF-REGULATORY STRATEGIES

interesting. It may be explained by people’s impression that physical effort is, while unpleasant, an indicator that one is improving one’s physical fitness ("no pain, no gain”) and may, like a form of positive feedback, even promote satisfaction with one’s persistence.

We furthermore found main effects on perceived self-regulatory success of five of the nine strategies. As predicted, two out of three strategies that were more frequently used by individuals with high levels of trait self-control, namely focusing on the positive consequences ( $B$ $=0.44,95 \%$ CI $[0.31,0.57], p<.001)$ and emotion regulation (not further specified) $(B=0.35$, 95\% CI [0.16, 0.54], $p<.001)$, had positive effects on perceived self-regulatory success. The third strategy goal setting had no positive effect on perceived self-regulatory success. Additionally, the strategies monitoring one's goal progress $(B=0.26,95 \% \mathrm{CI}[0.05,0.47], p=$ $.014)$, and thinking of the near finish $(B=0.34,95 \%$ CI $[0.19,0.48], p<.001)$ had positive effects on perceived self-regulatory success, even though they were not associated with trait selfcontrol. Lastly, distracting oneself from the activity $(B=-0.54,95 \%$ CI $[-0.75,-0.33], p<.001)$, a strategy also uncorrelated with trait self-control in the current study, had a negative effect on perceived self-regulatory success.

A few interaction effect with demands emerged in these analyses. To check the shapes of these interactions, we analyzed the simple slopes (on http://www.quantpsy.org/interact/hlm2.htm) for situations in which the respective demands were low (1 SD below the mean) and high (1 SD above the mean). First, task enrichment interacted with boredom ( $B=0.14,95 \%$ CI [0.02, 0.27], $p=.029)$. The simple slope analyses revealed that if boredom was low, task enrichment had no effect on perceived self-regulatory success (simple intercept: $B=4.76, S E=0.06, z=73.71, p<$ .001 ; simple slope: $B=0.27, S E=0.14, z=1.90, p=.058)$. If, however, boredom was high, task enrichment increased perceived self-regulatory success (simple intercept: $B=4.11, S E=0.08, z$ $=52.23, p<.001$, simple slope: $B=0.73, S E=0.34, z=2.13, p=.033)$. 
SELF-REGULATORY STRATEGIES

Second, both physical effort $(B=0.15,95 \%$ CI $[0.02,0.28], p=0.26)$ and emotional challenge $(B=0.14,95 \%$ CI $[0.09,0.28], p=.038)$ interacted with distracting oneself from the activity. The simple slopes analyses revealed that if physical effort or emotional challenge was low, distracting oneself from the activity was harmful to perceived self-regulatory success (for physical effort: simple intercept: $B=5.29, S E=0.06, z=88.64, p<.001$; simple slope: $B=$ $0.48, S E=0.11, z=-4.45, p<.001$; for emotional challenge: simple intercept: $B=4.80, S E=$ 0.07, $z=68.60, p<.001$, simple slope: $B=-0.34, S E=0.14, z=-2.52, p=.012)$. When physical effort or emotional challenge was high, distraction had no effect on perceived self-regulatory success (for physical effort: simple intercept: $B=5.68, S E=0.07, z=85.90, p<.001$; simple slope: $B=0.06, S E=0.29, z=0.23, p=.821$; for emotional challenge: simple intercept: $B=3.72$, $S E=0.14, z=26.49, p<.001$; simple slope: $B=0.14, z=0.43, p=.670$ ).

Third, physical effort interacted with focusing on the positive consequences $(B=-0.14$, 95\% CI [-0.23, -.0.05], $p=.002)$. When physical effort was low, focusing on positive consequences had a positive effect on perceived self-regulatory success (simple intercept: $B=$ 5.07, $S E=0.06, z=78.55, p<.001$; simple slope: $B=0.38, S E=0.07, z=5.33, p<.001)$. When physical effort was high, focusing on the positive consequences had no effect on perceived selfregulatory success (simple intercept: $B=5.73, S E=0.14, z=42.11, p<.001$; simple slope: $B=$ $0.12, S E=0.19, z=0.64, p=.520)$.

Finally both physical effort $(B=-0.15,95 \%$ CI $[-0.25,-0.06], p=.002)$ and emotional challenge ( $B=0.12,95 \%$ CI $[0.01,0.23], p=.030)$ interacted with thinking of the near finish. When physical effort was low, thinking of the near finish increased perceived self-regulatory success (simple intercept: $B=5.13, S E=0.06, z=81.93, \mathrm{p}<.001$; simple slope: $B=0.28, S E=$ $0.08, z=3.67, p<.001)$. When physical effort was high, thinking of the near finish had no effect on perceived self-regulatory success (simple intercept: $B=5.70, S E=0.12, z=47.33, p<.001$; 
SELF-REGULATORY STRATEGIES

simple slope: $B=-0.26, S E=0.21, z=-1.26, p=.207)$. Thinking of the near finish increased perceived self-regulatory success when emotional challenge was low (simple intercept: $B=4.62$, $S E=0.07, z=63.54, p<.001$; simple slope: $B=0.51, S E=0.11, z=4.68, p<.001$ ) and did so even more strongly when emotional challenge was high (simple intercept: $B=3.54, S E=0.15, z$ $=23.51, p<.001$; simple slope: $B=0.93, S E=0.28, z=3.30, p=.001$ ).

In sum, not all helpful strategies were perceived as equally helpful under all circumstances. Two strategies had stronger positive effects if certain types of demands were higher (task enrichment if boredom was high, thinking of the near finish when emotional challenge was high). Two strategies had more positive effects when physical effort was low (focusing on positive consequences and thinking of the near finish). Finally, one strategy, distracting oneself from the activity, was experienced as especially harmful when physical effort or emotional challenge were low. Overall, however, there were few interactions of strategies and demand types on perceived self-regulatory success.

\section{Mediation analyses: Does strategy use mediate effects of trait self-control on self-}

\section{perceived regulatory success?}

Finally, we continued to test our conceptual mediation model according to which individuals with high trait self-control are more likely to report using helpful strategies when confronted with an activity that challenges their self-regulation, and that this, in turn, accounts for their greater perceived momentary success in persisting during such an activity (see Table 5). We focused on the strategies that fulfilled the two necessary criteria for probing the mediation: First, they had to be predicted by trait self-control. Second, they had to be predictors of perceived selfregulatory success (effect of the mediator on the outcome). Two strategies fulfilled these two criteria, namely focusing on positive consequence and emotion regulation (not further specified), and were therefore retained for the mediation models. 
SELF-REGULATORY STRATEGIES

We also checked an additional precondition for the mediation models, namely that trait self-control positively predicted perceived self-regulatory success. This was the case $(B=0.34$, 95\% CI $[0.21,0.48], p<.001)$. We therefore continued to test a mediation model to see whether the two strategies focusing on positive consequences and emotion regulation (not further specified) as mediators would account for the positive effect of trait self-control on perceived self-regulatory success.

To test our multilevel mediation models with predictors on Level 2 and mediators and outcome on Level 1, we followed Preacher, Zyphur, and Zhang's (2010) recommendations (see model E in their Appendix). According to these authors, ordinary multilevel models would bias the indirect effect because they do not distinguish the within-effects from the between-effects of the level-1 mediator on the level-1 outcome. Because the effects of our level-2 predictor trait selfcontrol is a between-persons effects, any mediation of the level-2 predictors must also occur at the between-person level, and mediation effects on that level should be estimated without conflation from level-1 effects. We therefore report coefficients from models that estimate separately the within and the between components of the b-paths. While only the between components are of interest for the mediation models, the within component tells us something about the underlying processes. A significant within-effect indicates that using a strategy in a given moment increases perceived self-regulatory success in that moment, irrespective of the level-2 cluster, that is, whether that person tends to use strategies more or less often.

The results suggest that neither focusing on the positive consequences nor emotion regulation (not further specified) mediate the positive effects of trait self-control on perceived self-regulatory success in a given moment. In other words: The fact that individuals high in trait self-control more often focus of the positive consequences of unpleasant activities and regulate 
SELF-REGULATORY STRATEGIES

their emotions does not seem to explain their higher reported self-regulatory success in a given moment.

[Insert Table 5 here]

\section{General Discussion}

Many goals require engagement in activities that feel unpleasant, effortful, challenging, or boring. During such activities, a person may experience an intrapsychic conflict between what he or she should be doing (persist), and what he or she wants to do (something else) (Bazerman, Tenbrunsel, \& Wade-Benzoni, 1998; O’Connor et al., 2002). From an individual-difference perspective, the ability to resolve this conflict in the interest of one's goals is a relatively stable trait. Individual differences in trait self-control do indeed predict people’s success in attaining desirable outcomes like successful work or school performance (e.g., De Ridder et al., 2012; Tangney et al., 2004). Our data furthermore attests to the trait's predictive power, as it shows that individuals with high levels of trait self-control are indeed more successful in staying persistent during unpleasant activities in daily life. What had remained overlooked so far is how people high and low in the trait go about regulating their persistence during unpleasant or challenging goal pursuit in their daily lives.

The list of strategies we generated in Pilot Study 1 illustrates the potential variety of processes that individuals may deploy to self-regulate their persistence. It describes selfregulatory strategies at a useful level of abstraction that was (1) prompted by participants own responses, (2) appeared to provide a good balance between parsimony and differentiation during ambulatory assessment, and (3) matched well with constructs from the existing self-regulation literature. It moreover also included one new, not previously investigated self-regulatory strategy that was quite popular among our participants: Thinking of the near finish, which implies thinking that one will soon be done with the activity while performing it. 
SELF-REGULATORY STRATEGIES

Our Main Study supported that, in the face of an unpleasant or challenging task, people high in trait self-control help themselves persist by deploying three self-regulatory strategies: They more frequently focus on the positive consequences of the activity, set goals, and regulate their emotions. The strategies focusing on the positive consequences, regulating one's emotions, monitoring one's goal progress and thinking of the near finish were also reported as being effective in increasing participants' self-regulatory success in a given moment. In contrast, distracting oneself from the activity actually decreased subsequent perceived self-regulatory success in a given moment.

Finally, a multilevel mediation model revealed that the finding that individuals high in trait self-control more often focus on the positive consequences of unpleasant activities or regulate their emotions cannot explain their higher perceived self-regulatory success in a given moment. In sum, none of the self-regulatory strategies could explain the beneficial effect of trait self-control on self-regulation in a given moment.

\section{Self-Regulatory Strategies and Self-Regulatory Success}

The reported popularity of the 19 strategies was quite similar across Pilot Studies 2a, 2b, and the Main Study, despite the different assessment methods. Overall, focusing on the positive consequences of the activity was clearly the most popular method: In the Main Study, participants reported using it in more than one third of occasions at which they had to persist in an unpleasant or challenging activity. This is highly interesting, as prior evidence of the strategy’s instrumentality was rather mixed (see above). The character of the goal-relevant task might be an important moderator of the relationship between focusing on the positive consequences of goal attainment and persistence. Studies that found detrimental effects of focusing on positive consequences seem to have deployed somewhat less aversive tasks. For example, in Fishbach and Choi's (2012) four studies, irrespective of whether participants were 
SELF-REGULATORY STRATEGIES

instructed to focus on the outcomes or on the experience of an activity, experience ratings for the four goal-related activities of working out on a treadmill (Study $1, M=5.10$ and $M=5.78$, on a scale from 1-7), doing origami (Study 2, $M=4.54$ and $M=5.38$, on a scale from 1-7), flossing (Study 3, $M=5.96$ and $M=7.15$ on a scale from 1-9), and practicing yoga (Study $4, M=7.39$ and $M=8.13$ on a scale from 1-9) were all above the midpoints of the respective scales, indicating that these activities were somewhat pleasant. Freund and Hennecke (2012) investigated dieting which requires a multitude of activities that probably vary in their experience (e.g., from an enjoyable “stroll at the local farmer's market to get fresh vegetables” to a less enjoyable "cutting onions”). The conclusion that an outcome focus made the experience of these activities less positive and thereby reduced participants’ persistence may therefore hold for relatively pleasant activities but not for the aversive activities we have investigated in the research at hand. In fact, for relatively enjoyable activities, an effect akin to the crowding-out or undermining of intrinsic motivation (Deci, 1971; Kruglanski, Friedman, \& Zeevi, 1971; Lepper, Greene, \& Nisbett, 1973) may be responsible for the negative impact of focusing on their external instrumentality. But just as there is no undermining of intrinsic motivation through extrinsic incentives for non-enjoyable activities (Calder \& Staw, 1975), it may not undermine, but rather increase a person's persistence in a non-enjoyable activity, if he or she thinks about its positive consequences. Clearly, more research is needed to investigate whether task experience is in fact a moderator in the relationship between the self-regulatory strategy of focusing on positive consequences and persistence.

Three other strategies had positive reported self-regulatory effects, namely monitoring one's goal progress, thinking of the near finish, and emotion regulation (not further specified). With regard to the positive effects of monitoring one's progress, our results match well with theoretical considerations from control theory (e.g., Carver \& Scheier, 1982; Powers, 1973) and 
SELF-REGULATORY STRATEGIES

empirical results that were recently summarized in a meta-analysis (Harkin et al., 2016).

According to this meta-analysis interventions that promote goal progress monitoring are effective at improving goal attainment.

Thinking of the near finish by reminding oneself that one will soon be done with the unpleasant activity emerged as another positive predictor of perceived self-regulatory success. While being a highly effective strategy in our data, we were unable to identify previous research that has explicitly focused on the strategy’s application and adaptiveness. Generally, however, it has been shown that motivational strength and persistence increase with subjective proximity to a given goal (e.g., Förster, Higgins, \& Idson, 1998; Hull, 1932; Kivetz, Urminsky, \& Zheng, 2006). As a strategy, thinking of the near finish may involve self-talk that capitalizes on this effect. Obviously, thinking that one is "almost there" is a strategy of limited applicability as it probably supports persistence only when a goal-related activity is indeed almost completed. Supporting this notion, Koo and Fishbach (2012) have demonstrated that providing goal pursuers with information about how much more progress remains required before goal attainment increases motivation given that what is remaining is in fact smaller than the already accumulated goal progress.

As reviewed earlier, the ability to regulate one's emotions has emerged not only as an important contributor to daily well-being (Gross \& John, 2003). Recently, it has also been shown that individuals also regulate their feelings to help themselves attain instrumental goals like “getting work done” (English, Lee, John \& Gross, 2017), and that the ability to regulate one’s feelings is indeed a predictor of desirable outcomes like a more self-regulated eating behavior (Hofmann et al., 2009) or task performance at work (Carmeli \& Josman, 2006).

Distracting oneself from the activity emerged as a negative predictor of perceived selfregulatory success. While distraction has frequently been promoted as a useful self-regulatory 
SELF-REGULATORY STRATEGIES

strategy when individuals face a temptation (Metcalfe \& Mischel, 1999; Mischel et al., 1972), its detrimental effects in the current study support the notion that different forms of self-regulation (e.g., inhibition of desires vs. persistence) may require different strategies. It is possible that when individuals try to increase their persistence by focusing on something else than the current activity, it may undermine persistence by diverting attention away from the focal goal and towards more desirable activities.

It was surprising to us, to find no effects on perceived self-regulatory success for some strategies, like task enrichment or goal setting. For example, the positive effects of setting goals, as they are for example advocated in goal setting theory, have been shown many times (Kyllo \& Landers, 1995; Latham \& Kinne, 1974; Latham \& Marshall, 1982). One important aspect of goal setting theory is, however, that, in order to be effective, goals have to be specific and reasonably difficult to achieve. It is possible that when spontaneously setting their own goals, participants in our study may not have been very effective in formulating them in a way that actually helped their persistence. For example, a goal like “I’m going to do my best” should, according to goal setting theory (Locke \& Latham, 2002, 2006), not be very helpful, as opposed to, for example, a goal like “I’m going to continue studying until I have finished this chapter and I am able to give a quick summary of it.” It is also possible that participants set unrealistically ambitious goals, and that hence, with such high standards, they were in turn dissatisfied about their actual performance (Carver \& Scheier, 1990). As we did not collect information on the goals that participants set for themselves, we can neither confirm nor disconfirm that this explanation is responsible for the lack of an effect but it is a possibility.

\section{Implications for Self-Regulation Theories and Research}

One of the goals of the present research was to investigate whether strategy use is one of the processes through which trait self-control "gets outside the skin” (p. 315, Hampson, 2012). 
SELF-REGULATORY STRATEGIES

What we found is that individuals with high trait self-control do indeed use three strategies more often than individuals with lower levels of these traits, namely focusing on the positive consequences, goal setting, and emotion regulation (not further specified). However, none of these strategies accounted for the greater reported momentary self-regulatory success of people high in trait self-control. Accordingly, future research should continue to investigate the underlying explanatory mechanisms for self-regulatory ability for advancing a "whole trait” view (Fleeson \& Jayawickreme, 2015) of self-control. This view assumes that each trait has a descriptive side, that can be understood as the distribution of states (or "what one actually does", here: whether, over time, one is successfully in regulating one’s behavior), and an explanatory side, that consists of social-cognitive mechanisms that produce these states in response to relevant situations (here: aversive activities). Our data does not support that the strategies which participants explicitly report represent such social-cognitive mechanism. It is possible that more automatic processes that individuals may not be able to explicitly report are better candidates for explaining individual differences in self-control (e.g., Fishbach, Friedman, \& Kruglanski, 2003). Generally, a recent process-oriented perspective on self-regulation has furthermore begun to identify other explanatory constructs that, beyond the effortful inhibition of impulses, promote successful self-regulation (e.g., Duckworth et al., 2016a; Fujita, 2011; Gillebaart \& De Ridder, 2015). For example, individuals with high self-control appear to experience less or less severe self-control conflicts in the first place, possibly because they avoid tempting alternatives (Ent, Baumeister, \& Tice, 2015), experience their duties as more autonomously motivated (Converse et al., 2018), or have established habits that promote their goals (Galla \& Duckworth, 2015).

\section{Limitations and Future Directions}

We set out to study which strategies people spontaneously use in their everyday lives whenever they have to regulate their persistence during unpleasant activities. For the future, it 
SELF-REGULATORY STRATEGIES

would be desirable to extend this research to other, more diverse populations. While studies 2a and $2 \mathrm{~b}$ taken together reflect some diversity (with an English-speaking Mturk sample and a German-speaking sample with a substantial proportion of non-students), our Main Study is ultimately a study with a relatively young and well-educated sample. This may not be a large concern for the generalizability of within-participant processes-individual differences in trait self-control, for example, could be equally predictive of strategy use across different populations_-but our sample might face different self-regulatory challenges or prefer different self-regulatory strategies than other samples. Students, for example, are relatively autonomous when deciding when, where, and with whom to study and face a lot of mental (rather than, for example physical) challenges. Further, they tend to pursue a relatively abstract, but potentially intrinsically meaningful goal (e.g., becoming a psychologist). In contrast, blue-collar workers tend to be supervised more closely, are more likely to engage in a lot of monotonous or physically challenging work, and the most important positive consequence of their work may be a paycheck at the end of the month. It may be that the effectiveness of focusing on the positive consequences of an activity may be lower in such a case, where the consequence is highly extrinsic (Deci \& Ryan, 1985; Kruglanski et al., 1971; Lepper et al., 1973). Finally, strategies may vary in their effectiveness between different populations, for example, depending on individuals’ differing capacities to enact strategies effectively. Specifically, strategies that are very future-oriented (e.g., focusing on the positive consequences), that require a great deal of anticipation (e.g., focusing on the positive/negative consequences) or planning (e.g., planning/scheduling), or that are otherwise cognitively demanding may be usable and effective for some people but too taxing for others. The latter may instead prefer and be more successful with more ad-hoc in-the-moment strategies (e.g., adding something positive to the activity). At 
SELF-REGULATORY STRATEGIES

this point, all of this is speculative and future research will have to address potential moderator variables.

While the current research has shown that a person's trait self-control predicts which strategies that person prefers using, it says nothing about why a person, in a given moment, prefers using one strategy over another. It is probably the case that people more often use the strategies that they believe to be effective. In fact, in our Pilot Studies 2a and 2b, we also measured participants’ beliefs about the strategies’ effectiveness. These were highly correlated with participants' reported frequencies of strategy use (with $r$ s ranging from .42 to .79 across strategies). In the future, it would be interesting to investigate the role of subjective beliefs about strategy effectiveness in predicting strategy use more systematically. It is possible that individuals with high levels of trait self-control have more appropriate beliefs about what constitutes a suitable strategy in a given situation.

One aspect that we have not yet addressed, and that may also have important implications for self-regulatory success, is regulatory flexibility (Aldao, 2013; Bonanno \& Burton, 2013). In the literature on emotion regulation, it has been proposed that because the effectiveness of a given strategy is contingent on the context in which it is used, flexibility in using different kinds of strategies is advantageous. According to Bonanno and Burton (2013), flexibility encompasses three sequential components, namely (1) sensitivity to context, (2) availability of a broad repertoire of strategies, and (3) responsiveness to feedback. Transferred to self-regulation more broadly, the first component implies that a good self-regulator should be able to detect the demands of a given self-regulatory conflict and choose the appropriate strategy in response. This could imply using task enrichment if mental stimulation is too low, reducing distractions if there are too many, or setting goals or planning/scheduling if there is too little structure. The second component involves the necessity of actually having a sufficient number of self-regulatory 
SELF-REGULATORY STRATEGIES

strategies at one's disposal to flexibly switch between them if required. And the third component, involves that one can respond to feedback in order to make adjustments, that is, adjust a strategy or select a new one, given that the current one does not really match the situational demands. Future research may address, whether individual differences in trait self-control can, to some extent, be explained by differences in self-regulatory flexibility. Note, however, that in the present research, we did not find many interaction effects to indicate that a given strategy’s effectiveness varies much as a function of demands. This would also limit the advantages of regulatory flexibility. However, some of the strategies were rarely used in response to certain demands in our Main Study. Clearly, if a strategy is rarely used in combination with a certain demand, estimating its specific effectiveness for that activity or demand is quite unreliable. Here, experimental studies should augment our approach by systematically pairing strategies with different activities and demands. Moreover, our assessment of demands was clearly limited to a couple of items referring to mental effort, physical effort, boredom, and emotional challenges. A more fine-grained analysis of demands - including characteristics like the person's current autonomous vs. controlled motivation (Deci \& Ryan, 1985, 2000), their affective state, or level of fatigue - could also advance our understanding of regulatory flexibility.

Importantly, due to power concerns, we did not test the potential self-regulatory effects of strategies like planning/scheduling, adopting a process focus, reducing distractions, and reappraisal. These strategies may nevertheless have positive or negative effects and prior research clearly attests to the effectiveness of many of them (see Table 1). To study their effectiveness in an everyday context, an even more intense or longer ambulatory assessment seems necessary, so more occasions in which participants deployed these strategies could be assessed. 
SELF-REGULATORY STRATEGIES

Another limitation of our work lies in its strong reliance on self-report. First, there is the potential to overestimate associations between constructs due to shared method variance. Second, we cannot exclude other influences on our results; third variables like an overall positive selfregard may have inflated positive associations between strategy use and reported self-regulatory success. Moreover, a desire to experience cognitive consistency (Feldman, 1966; Festinger, 1957) may have led participants to retrospectively report using different (or fewer) strategies whenever they experienced themselves as unsuccessful in regulating their persistence. Thinking that one just has not used the right strategies may make it easier to cope with the feeling of failure. Vice versa, participants may feel that they might not have maximized persistence, if they did not use certain (or just any) strategies or they may feel that they must have maximized their persistence, if they used certain strategies and, in turn, be less or more satisfied, respectively. More generally, individuals may not always be able to properly remember and report intrapsychic processes like the deployment of self-regulatory strategies (Nisbett \& Wilson, 1977). While some regulatory processes like the strategies we focus on may be deployed explicitly, there are others that operate implicitly (e.g., “counteractive control”, Fishbach et al., 2003; Fishbach, Zhang, \& Trope, 2010). It is therefore important to acknowledge that this research is restricted to self-regulatory strategies that individuals use consciously, in response to the experience of a given activity as requiring the regulation of persistence.

However, in this domain of explicitly aversive experiences, self-regulatory strategies reflect controlled processes that individuals actively deploy (e.g., Metcalfe \& Mischel, 1999; Strack \& Deutsch, 2004) and that are probably at the higher end of the cognitive processes that people are able to report accurately (Hofmann, Friese, \& Wiers, 2008). Moreover, because many of the strategies are intrapsychic strategies (e.g., the most popular one, thinking of the positive consequences), and their deployment may not show in overt behavior, neither informant reports 
SELF-REGULATORY STRATEGIES

nor any behavioral measures would be good means of assessing them "in the wild.” Finally, it is not only common to assess regulatory attempts through self-report (like, e.g., in the emotion regulation literature) but there is also much evidence that these self-reports predict a variety of observable outcomes (e.g., English, John, Srivastava, \& Gross, 2012; Gross, 1998a; Gross \& John, 2003; Srivastava, Tamir, McGonigal, John, \& Gross, 2009), which attests to their validity. Additionally, rather than assessing strategy use retrospectively through a global self-report scale (as most commonly practiced), we assessed it using ambulatory assessment, which should allow for an even more reliable measure than in previous research. Nevertheless, it is important to keep the shortcomings of self-report in mind, when evaluating our results.

While a more objective measure of self-regulatory success would have been desirable, it is, however, difficult to imagine how we could have attained objective information about persistence for the wide range of activities that we covered in this study including studying, housework, or social contacts. If we were focusing only on one activity, e.g., persistence during exercise, this would be possible, for example, by tracking (through cellphone GPS) the time participants spend at the gym. However, it was an explicit goal of our research to not only focus on single goal-directed activities but to cover a wide range of activities.

Finally, in the main study, participants’ reports about their strategy use and self-regulatory success relied on single items, which may have increased measurement error. Note, however, that single-item measures are not, by definition, worse than multiple-item measures (Bergkvist \& Rossiter, 2007). Multiple-item measures are necessary for assessing broader constructs, e.g., personality. If, however, a construct is quite narrow, and we would suggest that the use of any single strategy is a narrow construct, single-item measures may, in fact, be sufficient (Sackett \& Larson, 1990). Moreover, single item measures of target constructs are very common in experience sampling studies (Hofmann et al., 2012; Milyavskaya \& Inzlicht, 2017; Milyavskaya 
SELF-REGULATORY STRATEGIES

et al., 2015; Friese \& Hofmann, 2016) and, in order to reduce participant burden, often the only feasible option.

\section{Conclusion}

According to our data, people quite frequently (in about $20 \%$ of all sampled occasions) engage in activities that are aversive or challenging. During such activities, people frequently have to somehow self-regulate their behavior in a way that allows them to persist. In the current research we have investigated this "somehow" with a focus on self-control as a trait and a wide range of self-regulatory strategies. We were able to identify strategies that, according to participants' reports, prevent and strategies that promote self-regulatory success during aversive activities in daily life. That these strategies did not depend on trait self-control nor explain the effects of trait self-control on momentary self-regulatory success, seems to show that trait selfcontrol and self-regulatory strategies represent separate routes to good self-regulation.

Studying persistence-aiding strategies seems worthwhile, because it completes the picture of the various possibilities of how self-regulation may look outside of the effortful inhibition of impulses. A focus on strategies of self-regulation and their effects on daily persistence may also help to link the somewhat dissociated research streams that have focused too exclusively on either the personality or the process side of successful self-regulation (Hoyle, 2006). Furthermore, insights from the field can provide an ecologically valid basis for recommendations on how individuals may improve their self-regulation in their everyday goal pursuits. By integrating trait- and process-approaches, our findings promote a more comprehensive understanding of self-regulatory success and failure during people’s daily attempts to regulate their persistence during aversive activities. 
SELF-REGULATORY STRATEGIES

\section{References}

Adriaanse, M. A., Kroese, F. M., Gillebaart, M., \& De Ridder, D. T. (2014). Effortless inhibition: Habit mediates the relation between self-control and unhealthy snack consumption. Frontiers in Psychology, 5, 444. doi: 10.3389/fpsyg.2014.00444

Agresti, A., Booth, J. G., Hobert, J. P., \& Caffo, B. (2000). Random-effects modeling of categorical response data. Sociological Methodology, 30, 27-80. doi:10.1111/00811750.t01-1-00075

Aldao, A. (2013). The future of emotion regulation research: Capturing context. Perspectives on Psychological Science, 8, 155-172. doi: 10.1177/1745691612459518

Bandura, A. (1976). Self-reinforcement: Theoretical and methodological considerations. Behaviorism, 4, 135-155.

Barrick, M. R., \& Mount, M. K. (1991). The Big Five personality dimensions and job performance: A meta-analysis. Personnel Psychology, 44, 1-26. doi:10.1111/j.17446570.1991.tb00688.x

Bates, D., Maechler, M., Bolker, B. \& Walker, S. (2015). Fitting linear mixed-effects models using lme4. Journal of Statistical Software, 67, 1-48.

Baumeister, R. F., Bratslavsky, E., Muraven, M., \& Tice, D. M. (1998). Ego depletion: Is the active self a limited resource? Journal of Personality and Social Psychology, 74, 1252-165. doi:10.1037/0022-3514.74.5.1252

Baumeister, R. F., Vohs, K. D., \& Tice, D. M. (2007). The strength model of self-control. Current Directions in Psychological Science, 16, 351-355. doi:10.1111/j.14678721.2007.00534.x 
SELF-REGULATORY STRATEGIES

Bazerman, M. H., Tenbrunsel, A. E., \& Wade-Benzoni, K. (1998). Negotiating with yourself and losing: Making decisions with competing internal preferences. Academy of Management Review, 23, 225-241. doi:10.5465/AMR.1998.533224

Bergkvist, L., \& Rossiter, J. R. (2007). The predictive validity of multiple-item versus singleitem measures of the same constructs. Journal of Marketing Research, 44, 175-184. doi: 10.1509/jmkr.44.2.175

Bertrams, A., \& Dickhäuser, O. (2009). Messung dispositioneller Selbstkontroll-Kapazität: Eine deutsche Adaptation der Kurzform der Self-Control Scale (SCS-KD). Diagnostica, 55, 210. doi:10.1026/0012-1924.55.1.2

Boekaerts, M. (1997). Self-regulated learning: A new concept embraced by researchers, policy makers, educators, teachers, and students. Learning and Instruction, 7, 161-186. doi:10.1016/S0959-4752(96)00015-1

Boggiano, A. K., Barrett, M., Weiher, A. W., McClelland, G. H., \& Lusk, C. M. (1987). Use of the maximal-operant principle to motivate children’s intrinsic interest. Journal of Personality and Social Psychology, 53, 866-879. doi:10.1037/0022-3514.53.5.866

Bonanno, G. A., \& Burton, C. L. (2013). Regulatory flexibility: An individual differences perspective on coping and emotion regulation. Perspectives on Psychological Science, 8, 591-612. doi: 10.1177/1745691613504116

Brickell, T. A., \& Chatzisarantis, N. L. (2007). Using self-determination theory to examine the motivational correlates and predictive utility of spontaneous exercise implementation intentions. Psychology of Sport and Exercise, 8, 758-770.

doi:10.1016/j.psychsport.2006.11.001 
SELF-REGULATORY STRATEGIES

Butler, D. (1998). The strategic content learning approach to promoting self-regulated learning: A report of three studies. Journal of Educational Psychology, 90, 682-697. doi: 10.1037/0022-0663.90.4.682

Calder, B. J., \& Staw, B. M. (1975). Self-perception of intrinsic and extrinsic motivation. Journal of Personality and Social Psychology, 31, 599-605. doi:10.1037/h0077100

Carmeli, A., \& Josman, Z. E. (2006). The relationship among emotional intelligence task performance, and organizational citizenship behaviors. Human Performance, 19, 403-419. doi:10.1207/s15327043hup1904_5

Carver, C. S., \& Scheier, M. F. (1982). Control theory: A useful conceptual framework for personality-social, clinical, and health psychology. Psychological Bulletin, 92(1), 111-135. doi: 10.1037/0033-2909.92.1.111

Carver, C. S., \& Scheier, M. F. (1990). Origins and functions of positive and negative affect: A control-process view. Psychological Review, 97, 19-35. doi:10.1037/0033-295X.97.1.19

Cheung, T. T., Gillebaart, M., Kroese, F., \& De Ridder, D. (2014). Why are people with high self-control happier? The effect of trait self-control on happiness as mediated by regulatory focus. Frontiers in Psychology, 5, 722. doi: 10.3389/fpsyg.2014.00722

Converse, B., Juarez, L., \& Hennecke, M. (2018). Self-control and the reasons behind our goals. Journal of Personality and Social Psychology. Advance online publication. doi: 10.1037/pspp0000188

Courneya, K. S., \& McAuley, E. (1991). Perceived effectiveness of motivational strategies to enhance children's intrinsic interest in sport and physical activity. Journal of Social Behavior and Personality, 6, 125-136.

Cramer, A. O. J., Van der Sluis, S., Noordhof, A., Wichers, M., Geschwind, N., Aggen, S. H, et al. (2012). Dimensions of normal personality as networks in search of equilibrium: You 
SELF-REGULATORY STRATEGIES

can’t like parties if you don’t like people. European Journal of Personality, 26(4), 414-431. doi: 10.1002/per.1866.

Curran, P. J., \& Bauer, D. J. (2011). The disaggregation of within-person and between-person effects in longitudinal models of change. Annual Review of Psychology, 62, 583-619. doi:10.1146/annurev.psych.093008.100356

Csikszentmihalyi, M., \& Larson, R. (1987). Validity and reliability of the Experience-Sampling Method. The Journal of Nervous and Mental Disease, 175, 526-536. doi: 10.1097/00005053-198709000-00004

Dahl, F. A., Grotle, M., Benth, J. Š., \& Natvig, B. (2008). Data splitting as a countermeasure against hypothesis fishing: with a case study of predictors for low back pain. European Journal of Epidemiology, 23, 237-242. doi: 10.1007/s10654-008-9230-x

Deci, E. L. (1971). Effects of externally mediated rewards on intrinsic motivation. Journal of Personality and Social Psychology, 18, 105-115. doi:10.1037/h0030644

Deci, E. L., \& Ryan, R. M. (1985). The general causality orientations scale: Self-determination in personality. Journal of Personality and Social Psychology, 19, 109-134. doi: 10.1016/00926566(85)90023-6

Deci, E. L., \& Ryan, R. M. (2000). The "what” and "why" of goal pursuits: Human needs and the self-determination of behavior. Psychological Inquiry, 11, 227-268. doi: 10.1207/s15327965pli1104_01

De Groot, A. D. (2014). The meaning of” significance” for different types of research [translated and annotated by Eric-Jan Wagenmakers, Denny Borsboom, Josine Verhafen, Rogier Kievit, Marjan Makker, Angelique Cramer, Dora Matzke, Don Mellenberg, and Han L. J. van der Maas]. Acta Psychologica, 148, 188-194. doi: 10.1016/j.actpsy.2014.02.001 
SELF-REGULATORY STRATEGIES

De Ridder, D. T., Lensvelt-Mulders, G., Finkenauer, C., Stok, F. M., \& Baumeister, R. F. (2012).

Taking stock of self-control: A meta-analysis of how trait self-control relates to a wide range of behaviors. Personality and Social Psychology Review, 16, 76-99.

doi:10.1177/1088868311418749

Dörrenbächer, L., \& Perels, F. (2016). Self-regulated learning profiles in college students: Their relationship to achievement, personality, and the effectiveness of an intervention to foster self-regulated learning. Learning and Individual Differences, 51, 229-241. doi: 10.1016/j.lindif.2016.09.015

Donnellan, M., Conger, R. D., \& Bryant, C. M. (2004). The Big Five and enduring marriages. Journal of Research in Personality, 38, 481-504. doi:10.1016/j.jrp.2004.01.001

Duckworth, A. L., Gendler, T. S., \& Gross, J. J. (2014). Self-control in school-age children. Educational Psychologist, 49, 199-217. doi:10.1080/00461520.2014.926225

Duckworth, A. L., Gendler, T. S., \& Gross, J. J. (2016a). Situational strategies for self-control. Perspectives on Psychological Science, 11, 35-55. doi:10.1177/1745691615623247

Duckworth, A.L., White, R.E., Matteucci, A.J., Shearer, A., \& Gross, J.J. (2016b). A stitch in time: Strategic self-control in high school and college students. Journal of Educational Psychology, 108, 329-341. doi: 10.1037/edu0000062

Elliot, A. J., \& Church, M. A. (1997). A hierarchical model of approach and avoidance achievement motivation. Journal of Personality and Social Psychology, 72, 218-232. doi: 10.1016/b978-012372545-5/50005-8

Elliot, A. J., McGregor, H. A., \& Gable, S. (1999). Achievement goals, study strategies, and exam performance: A mediational analysis. Journal of Experimental Social Psychology, 91, 549-563. doi:10.1037/0022-0663.91.3.549 
SELF-REGULATORY STRATEGIES

English, T., John, O. P., Srivastava, S., \& Gross, J. J. (2012). Emotion regulation and peer-rated social functioning: A 4-year longitudinal study. Journal of Research in Personality, 46(6), 780-784. doi: 10.1016/j.jrp.2012.09.006

English, T., Lee. I. A., John, O. P., \& Gross, J. J. (2017). Emotion regulation strategy selection in daily life: The role of social context and goals. Motivation and Emotion, 41, 230-242. doi: 10.1007/s11031-016-9597-z

Enders, C. K., \& Tofighi, D. (2007). Centering predictor variables in cross-sectional multilevel models: A new look at an old issue. Psychological Methods, 12, 121-138.

doi:10.1037/1082-989X.12.2.121

Ent, M. R., Baumeister, R. F., \& Tice, D. M. (2015). Trait self-control and the avoidance of temptation. Personality and Individual Differences, 74, 12-15. doi:

10.1016/j.paid.2014.09.031

Feldman, S. (Ed.). (1966). Cognitive consistency. New York, NY: Academic Press.

Festinger, L. (1957). A theory of cognitive dissonance. Evanston, IL: Row, Peterson.

Fleeson, W. (2001). Toward a structure-and process-integrated view of personality: Traits as density distributions of states. Journal of Personality and Social Psychology, 80, 10111027. doi: 10.1037/0022-3514.80.6.1011

Fleeson, W., \& Jayawickreme, E. (2015). Whole trait theory. Journal of Research in Personality, 56, 82-92. doi:10.1016/j.jrp.2014.10.009

Fleiss, J. L., Levin, B., \& Paik, M. C. (1981). The measurement of interrater agreement. In J. L. Fleiss, B. Levin, \& M. C. Paik, Statistical methods for rates and proportions (pp. 598-626). Hoboken, NJ: John Wiley \& Sons. 
SELF-REGULATORY STRATEGIES

Fishbach, A., \& Choi, J. (2012). When thinking about goals undermines goal pursuit.

Organizational Behavior and Human Decision Processes, 118, 99-107.

doi:10.1016/j.obhdp.2012.02.003

Fishbach, A., Friedman, R. S., \& Kruglanski, A. W. (2003). Leading us not into temptation:

Momentary allurements elicit overriding goal activation. Journal of Personality and Social Psychology, 84, 296-309. doi:10.1037/0022-3514.84.2.296

Fishbach, A., Zhang, Y., \& Trope, Y. (2010). Counteractive evaluation: Asymmetric shifts in the implicit value of conflicting motivations. Journal of Experimental Social Psychology, 46, 29-38. doi: 10.1016/j.jesp.2009.09.008

Förster, J., Higgins, E. T., \& Idson, L. C. (1998). Approach and avoidance strength during goal attainment: Regulatory focus and the "goal looms larger” effect. Journal of Personality and Social Psychology, 75, 1115-1131. doi:10.1037/0022-3514.75.5.1115

Forstmeier, W., Wagenmakers, E. J., \& Parker, T. H. (2016). Detecting and avoiding likely falsepositive findings-a practical guide. Biological Reviews, 2016, 1-28. doi: 10.1111/brv.12315

Freund, A. M., \& Hennecke, M. (2012). Changing eating behaviour vs. losing weight: The role of goal focus for weight loss in overweight women. Psychology and Health, 7, 25-42. doi:10.1080/08870446.2011.570867

Freund, A. M., \& Hennecke, M. (2015). On means and ends: The role of goal focus in successful goal pursuit. Current Directions in Psychological Science, 24, 149-153. doi:10.1177/0963721414559774

Friese, M., \& Hofmann, W. (2016). State mindfulness, self-regulation, and emotional experience in everyday life. Motivation Science, 2, 1-14. doi:10.1037/mot0000027 
SELF-REGULATORY STRATEGIES

Fujita, K. (2011). On conceptualizing self-control as more than the effortful inhibition of impulses. Personality and Social Psychology Review, 15, 352-366. doi:10.1177/1088868311411165

Fujita, K., Trope, Y., Liberman, N., \& Levin-Sagi, M. (2006). Construal levels and self-control. Journal of Personality and Social Psychology, 90, 351-367. doi:10.1037/00223514.90.3.351

Funder, D.C. (2001). Personality. Annual Review of Psychology, 52, 197-221. doi:10.1146/annurev.psych.52.1.197

Galla, B. M., \& Duckworth, A. L. (2015). More than resisting temptation: Beneficial habits mediate the relationship between self-control and positive life outcomes. Journal of Personality and Social Psychology, 109, 508-525. doi: 10.1037/pspp0000026

Gillebaart, M., Schneider, I. K., \& De Ridder, D. T. D. (2015). Effects of trait self-control on response conflict about healthy and unhealthy food. Journal of Personality, 84, 789-798. doi:10.1111/jopy.12219

Goldberg, L. R. (1999). A broad-bandwidth, public domain, personality inventory measuring the lower-level facets of several five-factor models. In V. I. Mervielde, I. Deary, F. De Fruyt, \& F. Ostendorf (Eds.), Personality psychology in Europe (Vol. 7, pp. 7-28). Tilburg, The Netherlands: Tilburg University Press.

Gollwitzer, P. M. (1999). Implementation intentions: Strong effects of simple plans. American Psychologist, 54, 493-503. doi:10.1037/0003-066X.54.7.493

Gollwitzer, P. M., \& Brandstätter, V. (1997). Implementation intentions and effective goal pursuit. Journal of Personality and Social Psychology, 73, 186-199. doi:10.1037/00223514.73.1.186 
SELF-REGULATORY STRATEGIES

Gollwitzer, P. M., \& Sheeran, P. (2006). Implementation intentions and goal achievement: A meta-analysis of effects and processes. Advances in Experimental Social Psychology, 38, 69-119. doi:10.1016/S0065-2601(06)38002-1

Green-Demers, I., Pelletier, L. G., Stewart, D. G., \& Gushue, N. R. (1998). Coping with the less interesting aspects of training: Toward a model of interest and motivation enhancement in individual sports. Basic and Applied Social Psychology, 20, 251-261. doi:10.1207/s15324834basp2004_2

Gross, J. J. (1998a). Antecedent-and response-focused emotion regulation: Divergent consequences for experience, expression, and physiology. Journal of Personality and Social Psychology, 74, 224-237. doi:10.1037/0022-3514.74.1.224

Gross, J. J. (1998b). The emerging field of emotion regulation: An integrative review. Review of General Psychology, 2, 271-299. doi:10.1037/1089-2680.2.3.271

Gross, J. J., \& John, O. P. (2003). Individual differences in two emotion regulation processes: Implications for affect, relationships, and well-being. Journal of Personality and social Psychology, 85, 348-362. doi:10.1037/0022-3514.85.2.348

Hampson, S. E. (2012). Personality processes: Mechanisms by which personality traits "get outside the skin”. Annual Review of Psychology, 63, 315-339. doi:10.1146/annurev-psych120710-100419

Harkin, B., Webb, T. L., Chang, B. P., Prestwich, A., Conner, M., Kellar, I., ... \& Sheeran, P. (2016). Does monitoring goal progress promote goal attainment? A meta-analysis of the experimental evidence. Psychological Bulletin, 142, 198-229. doi:10.1037/bul0000025

Hartford, A., \& Davidian, M. (2000). Consequences of misspecifying assumptions in nonlinear mixed effects models. Computational Statistics \& Data Analysis, 34, 139-164. doi:10.1016/S0167-9473(99)00076-6 
SELF-REGULATORY STRATEGIES

Hebb, D. O., \& Thompson, W. R. (1954). The social significance of animal studies. In G. Lindzey (Ed.), Handbook of Social Psychology (pp. 551-552). Reading, MA.: AddisonWesley.

Higgins, E. T. (1987). Self-discrepancy: A theory relating self and affect. Psychological Review, 94, 319-340. doi:10.1037/0033-295X.94.3.319

Higgins, E. T. (2012). Beyond pleasure and pain: How motivation works. New York, NY: Oxford University Press.

Hoffman, L., \& Stawski, R. S. (2009). Persons as contexts: Evaluating between-person and within-person effects in longitudinal analysis. Research in Human Development, 6, 97-120. doi:10.1080/15427600902911189

Hofmann, W., Baumeister, R. F., Förster, G., \& Vohs, K. D. (2012). Everyday temptations: An experience sampling study of desire, conflict, and self-control. Journal of Personality and Social Psychology, 102, 1318-1335. doi:10.1037/a0026545

Hofmann, W., Friese, M., \& Roefs, A. (2009). Three ways to resist temptation: The independent contributions of executive attention, inhibitory control, and affect regulation to the impulse control of eating behavior. Journal of Experimental Social Psychology, 45, 431-435. doi:10.1016/j.jesp.2008.09.013

Hofmann, W., Friese, M., \& Wiers, R. W. (2008). Impulsive versus reflective influences on health behavior: A theoretical framework and empirical review. Health Psychology Review, 2, 111-137. doi:10.1080/17437190802617668

Hofmann, W., \& Patel, P. V. (2015). SurveySignal: A convenient solution for experience sampling research using participants’ own smartphones. Social Science Computer Review, 33, 235-253. doi: 10.1177/0894439314525117 
SELF-REGULATORY STRATEGIES

Hox, J. J. (2010). Multilevel analysis: Techniques and applications (2. ed.). New York, NY: Routledge.

Hoyle, R. H. (2006). Personality and self-regulation: Trait and information-processing perspectives. Journal of Personality, 74, 1507-1525. doi:10.1111/j.14676494.2006.00418.x

Hoyle, R. H., \& Davisson, E. K. (2016). Varieties of self-control and their personality correlates. In K. D. Vohs \& R. F. Baumeister (Eds.), Handbook of self-regulation: Research, theory, and applications (pp. 396-413). New York, NY: The Guilford Press.

Hull, C. L. (1932). The goal-gradient hypothesis and maze learning. Psychological Review, 39, 25-34. doi:10.1037/h0072640

Impett, E. A., Strachman, A., Finkel, E. J., \& Gable, S. L. (2008). Maintaining sexual desire in intimate relationships: The importance of approach goals. Journal of Personality and Social Psychology, 94, 808-823. doi: 10.1037/0022-3514.94.5.808

Kahneman, D., Krueger, A. B., Schkade, D. A., Schwarz, N., \& Stone, A. A. (2004). A survey method for characterizing daily life experience: The day reconstruction method. Science, 306, 1776-1780. doi:10.1126/science.1103572

Kennedy, B. A., \& Miller, D. J. (1976). Persistent use of verbal rehearsal as a function of information about its value. Child Development, 566-569. doi: 10.2307/1128824

Kivetz, R., Urminsky, O., \& Zheng, Y. (2006). The goal-gradient hypothesis resurrected: Purchase acceleration, illusionary goal progress, and customer retention. Journal of Marketing Research, 43, 39-58. doi:10.1509/jmkr.43.1.39

Koo, M., \& Fishbach, A. (2012). The small-area hypothesis: Effects of progress monitoring on goal adherence. Journal of Consumer Research, 39, 493-509. doi:10.1086/663827

Kreft, I., \& de Leeuw, J. (1998). Introducing multilevel modeling. Thousand Oaks, CA: Sage. 
SELF-REGULATORY STRATEGIES

Kruglanski, A. W., Friedman, I., \& Zeevi, G. (1971). The effects of extrinsic incentive on some qualitative aspects of task performance. Journal of Personality, 39, 606-617. doi:10.1111/j.1467-6494.1971.tb00066.x

Kuhl, J. (1984). Volitional aspects of achievement motivation and learned helplessness: Toward a comprehensive theory of action control. Progress in Experimental Personality Research, 13, 99-171. doi:10.1016/b978-0-12-541413-5.50007-3

Kyllo, L. B., \& Landers, D. M. (1995). Goal setting in sport and exercise: A research synthesis to resolve the controversy. Journal of Sport and Exercise Psychology, 17, 117-137. doi:10.1123/jsep.17.2.117

Latham, G. P., \& Kinne, S. B. (1974). Improving job performance through training in goal setting. Journal of Applied Psychology, 59, 187-191. doi:10.1037/h0036530

Latham, G. P., \& Marshall, H. A. (1982). The effects of self-set, participatively set and assigned goals on the performance of government employees. Personnel Psychology, 35, 399-404. doi:10.1111/j.1744-6570.1982.tb02204.x

Lepper, M. R., Greene, D., \& Nisbett, R. E. (1973). Undermining children’s intrinsic interest with extrinsic reward: A test of the “overjustification” hypothesis. Journal of Personality and social Psychology, 28, 129-137. doi:10.1037/h0035519

Locke, E. A., \& Latham, G. P. (2002). Building a practically useful theory of goal setting and task motivation: A 35-year odyssey. American Psychologist, 57, 705-717. doi:10.1037/0003-066X.57.9.705

Locke, E. A., \& Latham, G. P. (2006). New directions in goal-setting theory. Current Directions in Psychological Science, 15, 265-268. doi:10.1111/j.1467-8721.2006.00449.x 
SELF-REGULATORY STRATEGIES

McCabe, K. O., \& Fleeson, W. (2016). Are traits useful? Explaining trait manifestations as tools in the pursuit of goals. Journal of Personality and Social Psychology, 110, 287-301. doi: 10.1037/a0039490

Metcalfe, J., \& Mischel, W. (1999). A hot/cool system analysis of delay of gratification: Dynamics of willpower. Psychological Review, 106, 3-19. doi:10.1037/0033-295x.106.1.3

Michalos, A. C. (1985). Multiple discrepancies theory (MDT). Social Indicators Research, 16, 347-413. doi:10.1007/BF00333288

Milyavskaya, M., \& Inzlicht, M. (2017). What's so great about self-control? Examining the importance of effortful self-control and temptation in predicting real-life depletion and goal attainment. Social Psychological and Personality Science. doi:10.1177/1948550616679237

Milyavskaya, M., Inzlicht, M., Hope, N., \& Koestner, R. (2015). Saying “no” to temptation: Want-to motivation improves self-regulation by reducing temptation rather than by increasing self-control. Journal of Personality and Social Psychology, 109, 677-693. doi:10.1037/pspp0000045

Mischel, W. (1981). Metacognition and the rules of delay. In J. J. Flavell \& L. Ross (Eds.), Social cognitive development: Frontiers and possible futures (pp. 240-271). Cambridge, England: Cambridge University Press.

Mischel, W., \& Baker, N. (1975). Cognitive appraisals and transformations in delay behavior. Journal of Personality and Social Psychology, 31, 254-261. doi:10.1037/h0076272

Mischel, W., Ebbesen, E. B., \& Raskoff Zeiss, A. (1972). Cognitive and attentional mechanisms in delay of gratification. Journal of Personality and Social Psychology, 21, 204-218. doi:10.1037/h0032198

Muthén, L.K., \& Muthén, B.O. (1998-2015). Mplus User’s Guide. Seventh Edition. Los Angeles, CA: Muthén \& Muthén. 
SELF-REGULATORY STRATEGIES

Mischel, H. N., \& Mischel, W. (1983). The development of children’s knowledge of self-control strategies. Child Development, 54, 603-619. doi: 10.2307/1130047

Nett, U. E., Goetz, T., \& Hall, N. C. (2011). Coping with boredom in school: An experience sampling perspective. Contemporary Educational Psychology, 36, 49-59. doi:10.1016/j.cedpsych.2010.10.003

Nielsen, S. G. (2004). Strategies and self-efficacy beliefs in instrumental and vocal individual practice: A study of students in higher music education. Psychology of Music, 32, 418-431. doi:10.1177/0305735604046099

Nisbett, R. E., \& Wilson, T. D. (1977). Telling more than we can know: Verbal reports on mental processes. Psychological Review, 84, 231-259. doi:10.1037/0033-295x.84.3.231

Nosek, B. A., Ebersole, C. R., DeHaven, A. C., \& Mellor, D. T. (2017). The Preregistration Revolution. Retrieved from https://osf.io/2dxu5

Nosek, B. A., \& Lakens, D. (2014). Registered reports. A method to increase the credibility of published results. Social Psychology, 45, 137-141. doi: 10.1027/1864-9335/a000192

O’Connor, K. M., De Dreu, C. K., Schroth, H., Barry, B., Lituchy, T. R., \& Bazerman, M. H. (2002). What we want to do versus what we think we should do: An empirical investigation of intrapersonal conflict. Journal of Behavioral Decision Making, 15, 403-418. doi:10.1002/bdm.426

Open Science Collaboration. (2015). Estimating the reproducibility of psychological science. Science, 349, 1-8. doi: 10.1126/science.aac4716

Ozer, D. J., \& Benet-Martinez, V. (2006). Personality and the prediction of consequential outcomes. Annual Review of Psychology, 57, 401-421.

doi:10.1146/annurev.psych.57.102904.190127 
SELF-REGULATORY STRATEGIES

Palmer, D. J., \& Goetz, E. T. (1988). Selection and use of study strategies: The role of the studier’s beliefs about self and strategies. In C. E. Weinstein, E. T. Goetz, P. A. Alexander (Eds.), Learning and study strategies: Issues in assessment, instruction, and evaluation (pp. 41-62). San Diego, CA: Academic Press.

Peake, P. K., Hebl, M., \& Mischel, W. (2002). Strategic attention deployment for delay of gratification in working and waiting situations. Developmental Psychology, 38, 313-326. doi:10.1037/0012-1649.38.2.313

Pintrich, P. R., \& De Groot, E. V. (1990). Motivational and self-regulated learning components of classroom academic performance. Journal of Educational Psychology, 82, 33-40. doi:10.1037/0022-0663.82.1.33

Powers, W. T. (1973). Feedback: Beyond Behaviorism: Stimulus-response laws are wholly predictable within a control-system model of behavioral organization. Science, 179(4071), 351-356. doi: 10.1126/science.179.4071.351

Preacher, K. J., Zyphur, M. J., \& Zhang, Z. (2010). A general multilevel SEM framework for assessing multilevel mediation. Psychological Methods, 15, 209-233.

doi:10.1037/a0020141

Raudenbush, S., Bryk, A., \& Congdon, R. (2013). HLM 7.01 for Windows [Hierarchical linear and nonlinear modeling software]. Los Angeles, CA: Multivariate Software.

R Core Team (2016). R: A language and environment for statistical computing. R Foundation for Statistical Computing, Vienna, Austria. https://www.R-project.org/

Revelle, W. (1995). Personality processes. Annual Review of Psychology, 46, 295-328. doi:10.1146/annurev.psych.46.1.295

Roberts, B. W., Kuncel, N. R., Shiner, R., Caspi, A., \& Goldberg, L. R. (2007). The power of personality: The comparative validity of personality traits, socioeconomic status, and 
SELF-REGULATORY STRATEGIES

cognitive ability for predicting important life outcomes. Perspectives on Psychological Science, 2, 313-345. doi:10.1111/j.1745-6916.2007.00047.x

Rodriguez, G., \& Goldman, N. (2001). Improved estimation procedures for multilevel models with binary response: A case-study. Journal of the Royal Statistical Society: Series A, 164, 339-355. doi:10.1111/1467-985X.00206

Rubin, M. (2017). Do $p$ values lose their meaning in exploratory analyses? It depends how you define the familywise error rate. Review of General Psychology, 21, 269-275. doi: 10.1037/gpr0000123

Sackett, P. R., \& Larson, J. R., Jr. (1990). Research strategies and tactics in industrial and organizational psychology. In M. D. Dunnette \& L. M. Hough (Eds.), Handbook of industrial and organizational psychology ( $2^{\text {nd }}$ ed., Vol. 1, pp. 419-489). Palo Alto, Ca: Consulting Psychologists Press.

Sansone, C., Weir, C., Harpster, L., \& Morgan, C. (1992). Once a boring task always a boring task? Interest as a self-regulatory mechanism. Journal of Personality and Social Psychology, 63, 379-390. doi:10.1037/0022-3514.63.3.379

Scherbaum, C. A. \& Ferreter, J. M. (2009). Estimating statistical power and required sample sizes for organizational research using multilevel modeling. Organizational Research Methods, 12, 2, 347-367, doi: 10.1177/1094428107308906

Schönbrodt, F. D., \& Perugini, M. (2013). At what sample size do correlations stabilize? Journal of Research in Personality, 47, 609-612. doi:10.1016/j.jrp.2013.05.009

Schunk, D. H., \& Zimmerman, B. J. (1994). Self-regulation of learning and performance: Issues and educational applications. Hillsdale, NJ: Lawrence Erlbaum Associates

Scollon, C., Prieto, C.-K., \& Diener, E. (2009). Experience sampling: Promises and pitfalls, strength and weaknesses. In E. Diener (Ed.), Social indicators research series: Assessing 
SELF-REGULATORY STRATEGIES

well-being (Vol. 39, pp. 157-180). Dordrecht, The Netherlands: Springer. doi:10.1007/97890-481-2354-4_8

Shah, J. Y., \& Kruglanski, A. W. (2003). When opportunity knocks: Bottom-up priming of goals by means and its effects on self-regulation. Journal of Personality and Social Psychology, 84, 1109-1122. doi:10.1037/0022-3514.84.6.1109

Srivastava, S., Tamir, M., McGonigal, K. M., John, O. P., \& Gross, J. J. (2009). The social costs of emotional suppression: A prospective study of the transition to college. Journal of Personality and Social Psychology, 96, 883-897. doi: 10.1037/a0014755

Strack, F., \& Deutsch, R. (2004). Reflective and impulsive determinants of social behavior. Personality and Social Psychology Review, 8, 220-247. doi:10.1207/s15327957pspr0803_1

Tangney, J. P., Baumeister, R. F., \& Boone, A. L. (2004). High self-control predicts good adjustment, less pathology, better grades, and interpersonal success. Journal of Personality, 72, 271-324. doi:10.1111/j.0022-3506.2004.00263.x

Wertenbroch, K. (1998). Consumption self-control by rationing purchase quantities of virtue and vice. Marketing Science, 17, 317-337. doi:10.1287/mksc.17.4.317

Woolley, K., \& Fishbach, A. (2015). The experience matters more than you think: People value intrinsic incentives more inside than outside an activity. Journal of Personality and Social Psychology, 109, 968-982. doi:10.1037/pspa0000035

Yeager, D. S., \& Dweck, C. S. (2012). Mindsets that promote resilience: When students believe that personal characteristics can be developed. Educational Psychologist, 47, 302-314. doi:0.1080/00461520.2012.722805

Zimmerman, B. J. (1990). Self-regulated learning and academic achievement: An overview. Educational Psychologist, 25, 3-17. doi: 10.1207/s15326985ep2501_2 
SELF-REGULATORY STRATEGIES

Zimmerman, B. J., \& Risemberg, R. (1997). Becoming a self-regulated writer: A social cognitive perspective. Contemporary Educational Psychology, 22, 73-101.

doi:10.1006/ceps.1997.0919 


\section{Tables}

Table 1

Strategy Descriptions and Strategy Use Items from Pilot Study $2 a$

Strategy

Description

English item from Pilot Study 2a

\section{Situation modification strategies}

1) Changing the activity itself

2) Changing the environment

3) Reducing distractions

4) Seeking social support

5) Taking a substance

6) Task enrichment

$$
\begin{aligned}
& \text { Adding some kind of (positive) stimulus input } \\
& \text { outside of the activity (e.g., music, TV, phone talk, } \\
& \text { food, drink) without changing the activity itself }
\end{aligned}
$$

Changing the nature of the activity itself or of how it is performed (without adding an incentive from the outside)

Changing the environment in which the activity is performed (unspecified whether this results in a fresh start, task enrichment, distraction of attention, or removal of distractions)

Reducing or removing distractors or temptations from one's environment

Using the support of others

Taking substances, drugs, medication

\section{Attentional deployment strategies}

7) Adopting a process focus
Focusing one's attention on how the activity is performed
I change the activity itself (e.g., run more slowly on the treadmill, take notes during studying).

I change the environment where I perform the activity (e.g., work from a coffee shop, take a new route when running).

I reduce or remove distractions and temptations.

I draw on the social support of others.

I take a substance or drug (e.g., coffee or energy drinks).

I add something positive to the activity to make it more pleasant (e.g., listen to music, watch TV while doing it).

I focus my attention on the activity itself and on the way I am performing it. 
8) Distracting oneself from the activity
Focusing one's attention on something else outside of the activity (without changing the activity itself or enriching the task by adding an outside incentive)
I distract my attention by focusing on something else outside of the activity.

\section{Cognitive change strategies}

9) Anticipating self-reward

10) Focusing on negative consequences

11) Focusing on positive consequences

12) Goal setting

13) Monitoring one's goal progress

14) Planning/ scheduling

15) Reappraisal

16) Self-talk

17) Thinking of the near finish
Adding a reward that is external to the activity or its goal

Thinking of negative consequences from non-pursuit of the activity, the prevention/avoidance goals that motivated the activity: Responses usually include negation (not being healthy), reference to negative outcome or reference to avoidance or prevention

Thinking of positive consequences from pursuit of the activity, the promotion/approach goals that motivated the activity: Responses usually include reference to a desirable outcome

\section{Committing to (sub)goals}

Checking one's progress

Making a schedule or plan (may include the setting of subgoals, but only when timing is also set)

Thinking differently of the activity or changing its meaning (without changing the activity itself)

\section{Motivating self-talk}

Thinking about (nearby) task completion (not about the long-term goals)
I later reward myself for performing the activity.

I think of the negative consequences that occur if I do not perform the activity.

I remind myself why I perform the activity and think of its positive consequences.

I define a specific goal or set subgoals for myself.

I check my goal progress.

I make a plan or set a specific time for engaging in the activity.

I think differently about the activity or change its meaning (e.g., imagine running in a race).

I talk to myself to motivate me.

I remind myself that soon $I$ will be done with the activity. 


\section{Response modulation strategy}

18) Suppressing the Inhibiting the impulse to quit

I suppress the impulse to quit. impulse to quit

\section{Not further specified strategy}

19) Emotion Regulating one's feelings (unspecified how this is regulation (not done)

I change how I feel (e.g., try to stay in a good mood). further specified) 
Table 2

Descriptive Statistics and Correlations of Self-Regulatory Strategy Use With Trait Self-Control (TSC) (Pilot Studies 2a and 2b)

\begin{tabular}{|c|c|c|c|c|c|c|c|c|c|c|}
\hline \multirow{3}{*}{ Variable } & \multicolumn{5}{|c|}{ Sample 2a } & \multicolumn{5}{|c|}{ Sample $2 \mathbf{b}$} \\
\hline & \multicolumn{4}{|c|}{$r$ with } & \multicolumn{6}{|c|}{$r$ with } \\
\hline & $M$ & $S D$ & TSC & $95 \% C I$ & $p$ & $M$ & $S D$ & TSC & $95 \% C I$ & $p$ \\
\hline Trait self-control & 4.47 & 1.18 & - & & & 4.12 & 0.92 & - & & \\
\hline \multicolumn{11}{|l|}{ Situation modification strategies } \\
\hline 1) Changing the activity itself & 2.93 & 0.95 & .06 & {$[-.07, .18]$} & .380 & 2.78 & 0.94 & -.02 & {$[-.15, .11]$} & .831 \\
\hline 2) Changing the environment & 2.80 & 1.09 & .16 & {$[.04, .28]$} & .013 & 2.92 & 1.09 & .11 & {$[-.02, .24]$} & .092 \\
\hline 3) Reducing distractions & 3.00 & 1.11 & .31 & {$[.19, .42]$} & $<.001$ & 3.01 & 1.03 & .24 & {$[.11, .36]$} & $<.001$ \\
\hline 4) Seeking social support & 2.45 & 1.17 & .13 & {$[.005, .25]$} & .045 & 2.71 & 0.97 & .00 & {$[-.13, .13]$} & .949 \\
\hline 5) Taking a substance & 2.44 & 1.24 & -.23 & {$[-.35,-.11]$} & $<.001$ & 2.34 & 1.18 & -.11 & {$[-.24, .02]$} & .118 \\
\hline 6) Task enrichment & .58 & 1.02 & -.22 & {$[-.34,-.10]$} & .001 & 3.37 & 1.03 & -.13 & {$[-.26, .002]$} & .060 \\
\hline \multicolumn{11}{|l|}{ Attentional deployment strategies } \\
\hline 7) Adopting a process focus & 3.40 & 0.98 & .25 & {$[.13, .36]$} & $<.001$ & 2.93 & 1.03 & .28 & {$[.15, .40]$} & $<.001$ \\
\hline $\begin{array}{l}\text { 8) Distracting oneself from the } \\
\text { activity }\end{array}$ & 2.91 & 1.10 & -.26 & {$[-.3$} & $<$. & 2.85 & 0.99 & -.25 & {$[-.37,-.12]$} & $<.001$ \\
\hline \multicolumn{11}{|l|}{ Cognitive change strategies } \\
\hline $\begin{array}{l}\text { 9) Anticipating self-reward } \\
\text { 10) Focusing on negative }\end{array}$ & 3.41 & 1.12 & .07 & {$[-.06, .19]$} & .284 & 3.52 & 1.02 & -.04 & {$[-.17, .09]$} & .519 \\
\hline $\begin{array}{l}\text { consequences } \\
\text { 11) Focusing on }\end{array}$ & 3.32 & 1.24 & -.14 & {$[-.26,-.02]$} & .027 & 3.23 & 1.14 & -.18 & {$[-.31,-.05]$} & .007 \\
\hline consequenc & 3.79 & 0.97 & .21 & {$[.09, .33]$} & .001 & 3.83 & 0.93 & .20 & {$[.07, .32]$} & $<.001$ \\
\hline 12) Goal setting & 3.60 & 1.06 & .26 & {$[.14, .37]$} & $<.001$ & 3.42 & 1.10 & .38 & {$[.26, .49]$} & $<.001$ \\
\hline 13) Monitoring one's goal & & & & & & & & & & 601 \\
\hline 14) Planning/scheduling & $\begin{array}{l}5.00 \\
3.40\end{array}$ & $\begin{array}{l}0.50 \\
1.04\end{array}$ & .14 & {$[.02, .26]$} & .150 & $\begin{array}{l}3.33 \\
3.42\end{array}$ & 1.07 & $\begin{array}{l}.25 \\
.30\end{array}$ & {$[.18, .42]$} & $<.001$ \\
\hline 15) Reappraisal & 2.70 & 1.12 & .17 & {$[.05, .29]$} & .010 & 2.29 & 0.95 & .17 & {$[.04, .30]$} & $<.013$ \\
\hline 16) Self-talk & 3.00 & 1.19 & .08 & {$[-.05, .20]$} & .197 & 2.84 & 1.21 & .03 & {$[-.10, .16]$} & .640 \\
\hline 17) Thinking of near finish & 3.58 & 0.95 & -.08 & {$[-.20, .05]$} & .193 & 3.52 & 0.90 & -.08 & {$[-.21, .05]$} & .244 \\
\hline
\end{tabular}

Response modulation strategy 
18) Suppressing the impulse to

Not further specified strategy

19) Emotion regulation (not

further specified)

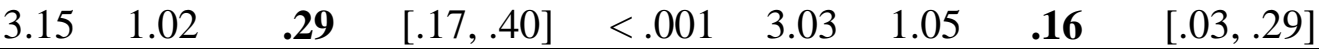

.016

Note. Ns range from 243 to 245 in Sample 2a and from 216 to 220 in Sample 2b. Significant correlation coefficients are written in bold. 
SELF-REGULATORY STRATEGIES

Table 3

Results from Multilevel Regression Models of Self-Regulatory Strategies on Activity Demands (ICCs for strategies are calculated based on models without predictors)

\begin{tabular}{|c|c|c|c|c|c|c|}
\hline \multirow[b]{2}{*}{ Predictor } & \multicolumn{3}{|c|}{ 6) Task enrichment } & \multicolumn{3}{|c|}{$\begin{array}{l}\text { 8) Distracting oneself } \\
\text { from the activity }\end{array}$} \\
\hline & $B_{\log }$ & $95 \% \mathrm{CI}$ & $p$ & $B_{\log }$ & $95 \% \mathrm{CI}$ & $p$ \\
\hline Intercept & -1.75 & {$[-2.00,-1.53]$} & $<.001$ & -2.24 & {$[0-2.49,-2.02]$} & $<.001$ \\
\hline Physical effort & 0.17 & {$[0.08,0.25]$} & $<.001$ & 0.01 & {$[0-0.10,0.11]$} & .883 \\
\hline Mental effort & -0.13 & {$[0-0.21,-0.04]$} & .004 & -0.11 & {$[0-0.21,-0.01]$} & .038 \\
\hline Emotional challenge & -0.14 & {$[0-0.23,-0.04]$} & .007 & 0.07 & {$[0-0.04,0.19]$} & .190 \\
\hline Boredom & 0.14 & {$[00.04,0.24]$} & .007 & 0.47 & {$[00.35,0.59]$} & $<.001$ \\
\hline ICC & \multicolumn{3}{|c|}{.26} & \multicolumn{3}{|c|}{.17} \\
\hline
\end{tabular}

Note. Predictors were group-mean centered. Significant $B_{\operatorname{logs}}$ are written in bold (except for significant intercepts).

Table 3 (continued)

\begin{tabular}{lcccccr}
\hline & \multicolumn{3}{c}{ 10) Focusing on negative } & \multicolumn{3}{c}{ 11) Focusing on positive } \\
consequences
\end{tabular}

Table 3 (continued)

12) Goal setting

\begin{tabular}{lrcrrcr} 
& \multicolumn{3}{c}{ progress } \\
\cline { 2 - 7 } Predictor & $B_{\log }$ & $95 \%$ CI & \multicolumn{1}{c}{$p$} & \multicolumn{1}{c}{$B_{\log }$} & $95 \%$ CI & \multicolumn{1}{c}{$p$} \\
\hline Intercept & -2.66 & {$[-2.97,-2.40]$} & $<.001$ & -2.48 & {$[-2.78,-2.23]$} & $<.001$ \\
Physical effort & 0.00 & {$[-0.12,0.11]$} & .954 & 0.01 & {$[-0.09,0.11]$} & .808 \\
Mental effort & $\mathbf{0 . 1 7}$ & {$[0.04,0.30]$} & .012 & $\mathbf{0 . 1 6}$ & {$[0.04,0.27]$} & .008 \\
Emotional challenge & $\mathbf{- 0 . 1 4}$ & {$[-0.27,-0.02]$} & .030 & $\mathbf{- 0 . 2 2}$ & {$[-0.34,-0.10]$} & $<.001$ \\
Boredom & $\mathbf{- 0 . 1 8}$ & {$[-0.32,-0.04]$} & .012 & $\mathbf{- 0 . 1 3}$ & {$[-0.26,-0.01]$} & .041 \\
\hline ICC & \multicolumn{3}{c}{.22} & & \multicolumn{4}{c}{.25} & \\
\hline
\end{tabular}


SELF-REGULATORY STRATEGIES

Table 3 (continued)

\begin{tabular}{lrccccc}
\hline & \multicolumn{3}{c}{ 17) Thinking of the near finish } & \multicolumn{4}{c}{ 18) Suppressing the desire to quit } \\
\cline { 2 - 7 } Predictor & \multicolumn{1}{c}{$B_{\log }$} & $95 \%$ CI & $p$ & \multicolumn{1}{c}{$B_{\log }$} & 95\% CI & $p$ \\
\hline Intercept & -1.07 & {$[-1.25,-0.91]$} & $<.001$ & -2.20 & {$[-2.47,-1.95]$} & $<.001$ \\
Physical effort & 0.04 & {$[-0.04,0.11]$} & .320 & 0.05 & {$[-0.05,0.14]$} & .342 \\
Mental effort & $\mathbf{0 . 0 9}$ & {$[0.01,0.17]$} & .034 & $\mathbf{0 . 1 3}$ & {$[0.03,0.24]$} & .014 \\
Emotional challenge & $\mathbf{- 0 . 1 0}$ & {$[-0.18,-0.01]$} & .027 & 0.10 & $-[0.01,0.20]$ & .066 \\
Boredom & $\mathbf{0 . 1 7}$ & {$[0.08,0.26]$} & $<.001$ & 0.08 & $-[0.03,0.19]$ & .158 \\
\hline ICC & \multicolumn{7}{c}{} & .18 & .30 & \\
\hline
\end{tabular}

Table 3 (continued)

\begin{tabular}{lrcr}
\hline & \multicolumn{3}{c}{$\begin{array}{c}\text { 19) Emotion regulation } \\
\text { (not further specified) }\end{array}$} \\
\cline { 2 - 4 } Predictor & \multicolumn{1}{c}{$B_{\log }$} & $95 \%$ CI & $p$ \\
\hline Intercept & -2.30 & {$[-2.61,-2.04]$} & $<.001$ \\
Physical effort & 0.01 & {$[-0.09,0.11]$} & .866 \\
Mental effort & 0.03 & {$[-0.08,0.14]$} & .586 \\
Emotional challenge & -0.01 & {$[-0.12,0.10]$} & .898 \\
Boredom & $\mathbf{- 0 . 2 8}$ & {$[-0.40,-0.16]$} & $<.001$ \\
\hline ICC & \multicolumn{4}{c}{.34} \\
\hline
\end{tabular}


SELF-REGULATORY STRATEGIES

Table 4

Results from Multilevel Regression Models of Self-Regulatory Strategy Use on Trait Self-Control (Main Study)

\begin{tabular}{lcccccc}
\hline & \multicolumn{3}{c}{$\begin{array}{c}\text { 8) Distracting oneself } \\
\text { from the activity }\end{array}$} & \multicolumn{3}{c}{$\begin{array}{c}\text { 10) Focusing on negative } \\
\text { consequences }\end{array}$} \\
\cline { 2 - 7 } Predictor & $B_{\log }$ & $95 \%$ CI & $p$ & $B_{\log }$ & $95 \%$ CI & $p$ \\
\hline Intercept & -2.06 & {$[-2.29,-1.86]$} & $<.001$ & -2.03 & {$[-2.30,-1.79]$} & $<.001$ \\
Trait self-control & -0.19 & {$[-0.40,0.01]$} & .066 & -0.06 & {$[-0.30,0.17]$} & .604 \\
\hline $\begin{array}{l}\text { Note. Predictors were grand-mean centered. Significant } B_{\operatorname{logs}} \text { are written in bold (except for } \\
\text { significant intercepts). }\end{array}$
\end{tabular}

Table 4 (continued)

\begin{tabular}{lcccccc}
\hline & \multicolumn{3}{c}{ 11) Focusing on positive } & \multicolumn{3}{c}{ 12) Goal setting } \\
& \multicolumn{3}{c}{ consequences } & & & \\
\cline { 2 - 6 } Predictor & $B_{\log }$ & $95 \%$ CI & $p$ & $B_{\log }$ & $95 \%$ CI & $p$ \\
\hline Intercept & -0.63 & {$[-0.79,-0.47]$} & $<.001$ & -2.60 & {$[-2.89,-2.36]$} & $<.001$ \\
Trait self-control & $\mathbf{0 . 3 1}$ & {$[0.14,0.49]$} & $<.001$ & $\mathbf{0 . 4 5}$ & {$[0.21,0.69]$} & $<.001$ \\
\hline
\end{tabular}

Table 4 (continued)

19) Emotion regulation

\begin{tabular}{lccc} 
& \multicolumn{3}{c}{ (not further specified) } \\
\cline { 2 - 4 } Predictor & $B_{\log }$ & $95 \%$ CI & $p$ \\
\hline Intercept & -2.22 & {$[-2.50,-1.97]$} & $<.001$ \\
Trait self-control & $\mathbf{0 . 4 0}$ & {$[0.17,0.65]$} & .001 \\
\hline
\end{tabular}


SELF-REGULATORY STRATEGIES

Table 5

Results from the Multilevel Mediation Model Predicting Perceived Self-Regulatory Success from Trait Self-Control through Self-Regulatory Strategy Use (Main Study)

\begin{tabular}{lcccc}
\hline Path & $B$ & $95 \%$ CI & $p$ \\
\hline $\begin{array}{l}\text { Between-person effects } \\
\text { a1: Focusing on positive consequences predicted }\end{array}$ & $\mathbf{0 . 2 4}$ & {$[0.15 ; 0.34]$} & $<.001$ \\
$\begin{array}{l}\text { by trait self-control } \\
\text { a2: Emotion regulation (not further specified) }\end{array}$ & $\mathbf{0 . 2 9}$ & {$[0.17 ; 0.41]$} & $<.001$ \\
$\begin{array}{l}\text { predicted by trait self-control } \\
\text { b1: Subjective self-regulatory success predicted }\end{array}$ & & & & \\
$\begin{array}{l}\text { by focusing on positive consequences } \\
\text { b2: Subjective self-regulatory success predicted }\end{array}$ & -0.13 & {$[-0.11 ; 0.48]$} & .371 \\
$\begin{array}{l}\text { by emotion regulation (not further specified) } \\
\text { ': Subjective self-regulatory success predicted }\end{array}$ & $\mathbf{0 . 3 5}$ & {$[0.21 ; 0.16]$} & .843 \\
$\begin{array}{l}\text { by trait self-control } \\
\text { Within-person effects }\end{array}$ & & & & \\
\hline $\begin{array}{l}\text { b1w: Subjective self-regulatory success } \\
\text { predicted by focusing on positive consequences }\end{array}$ & $\mathbf{0 . 3 4}$ & {$[0.27 ; 0.40]$} & $<.001$ \\
$\begin{array}{l}\text { b2w: Subjective self-regulatory success } \\
\text { predicted by emotion regulation (not further }\end{array}$ & $\mathbf{0 . 2 5}$ & {$[0.15 ; 0.35]$} & $<.001$ \\
$\begin{array}{l}\text { specified) } \\
\text { Indirect effects }\end{array}$ & & & & \\
\hline $\begin{array}{l}\text { a1*b1 } \\
\text { a2*b2 }\end{array}$ & 0.03 & {$[-0.03 ; 0.09]$} & .373 \\
\hline
\end{tabular}

Note. Trait self-control was grand-centered, focusing on positive consequences and emotion regulation (not further specified) were person-centered prior to this analysis. Significant coefficients are written in bold. ICC for focusing on positive consequences $=.24$, ICC for emotion regulation (not further specified) $=.35$, ICC for subjective self-regulatory success $=.20$; Residual variance for subjective self-regulatory success $=1.85(S E=0.06, p<.001)$. 


\section{Figures}

9) Anticipating self-reward

10) Focusing on negative consequences

11) Focusing on positive consequences

12) Goal setting

13) Monitoring one's goal progress

14) Planning/scheduling

15) Reappraisal

16) Self-talk

17) Thinking of the near finish

7) Adopting a process focus 8) Distracting oneself from the activity

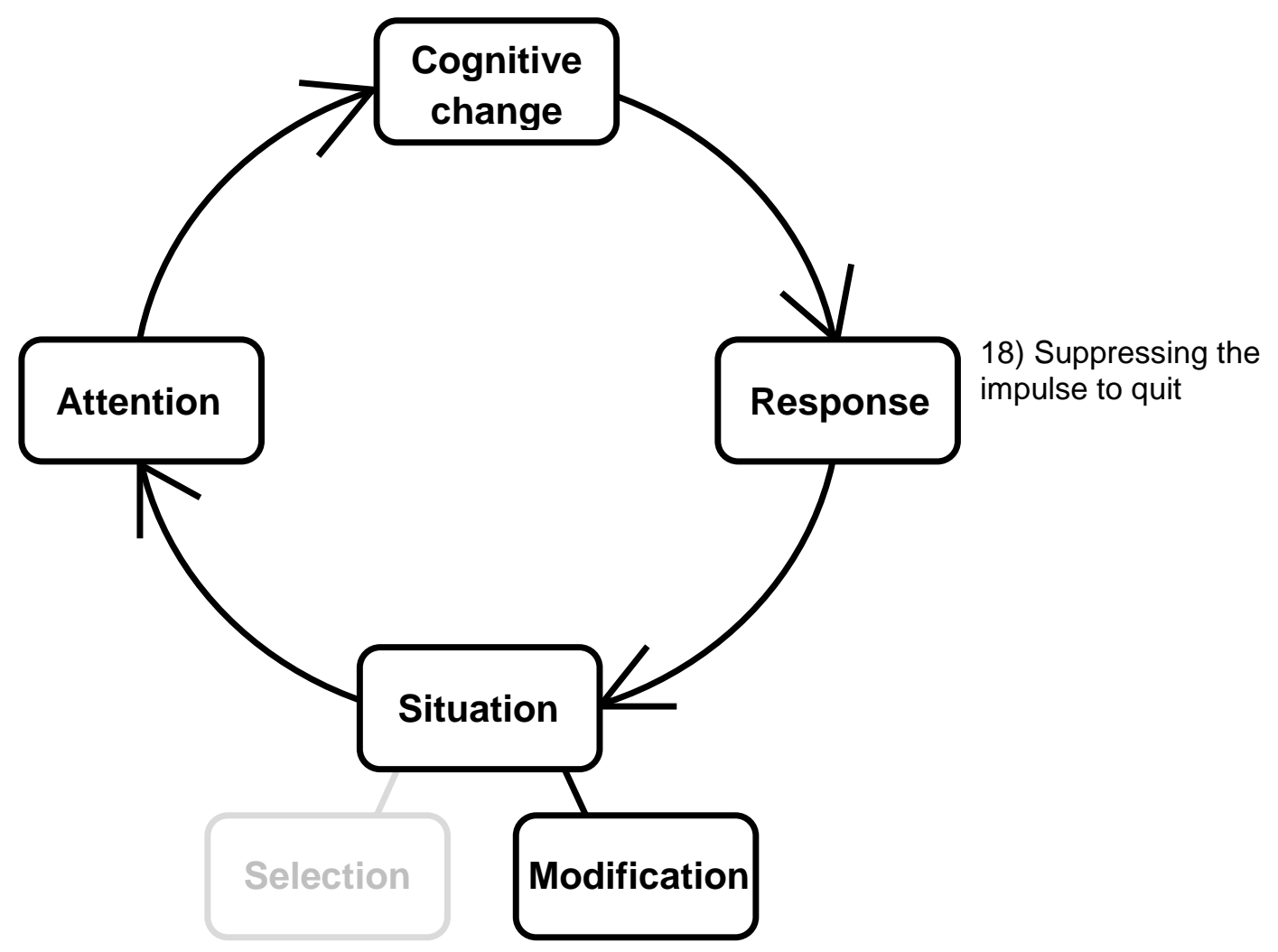

1) Changing the activity itself

2) Changing the environment

3) Reducing distractions

4) Seeking social support

5) Taking a substance

6) Task enrichment

19) Emotion regulation (not further specified)

Figure 1. Assignment of strategies to categories of self-regulatory strategies in Duckworth et al.'s (2016a, 2016b) process model of self-regulation 
SELF-REGULATORY STRATEGIES

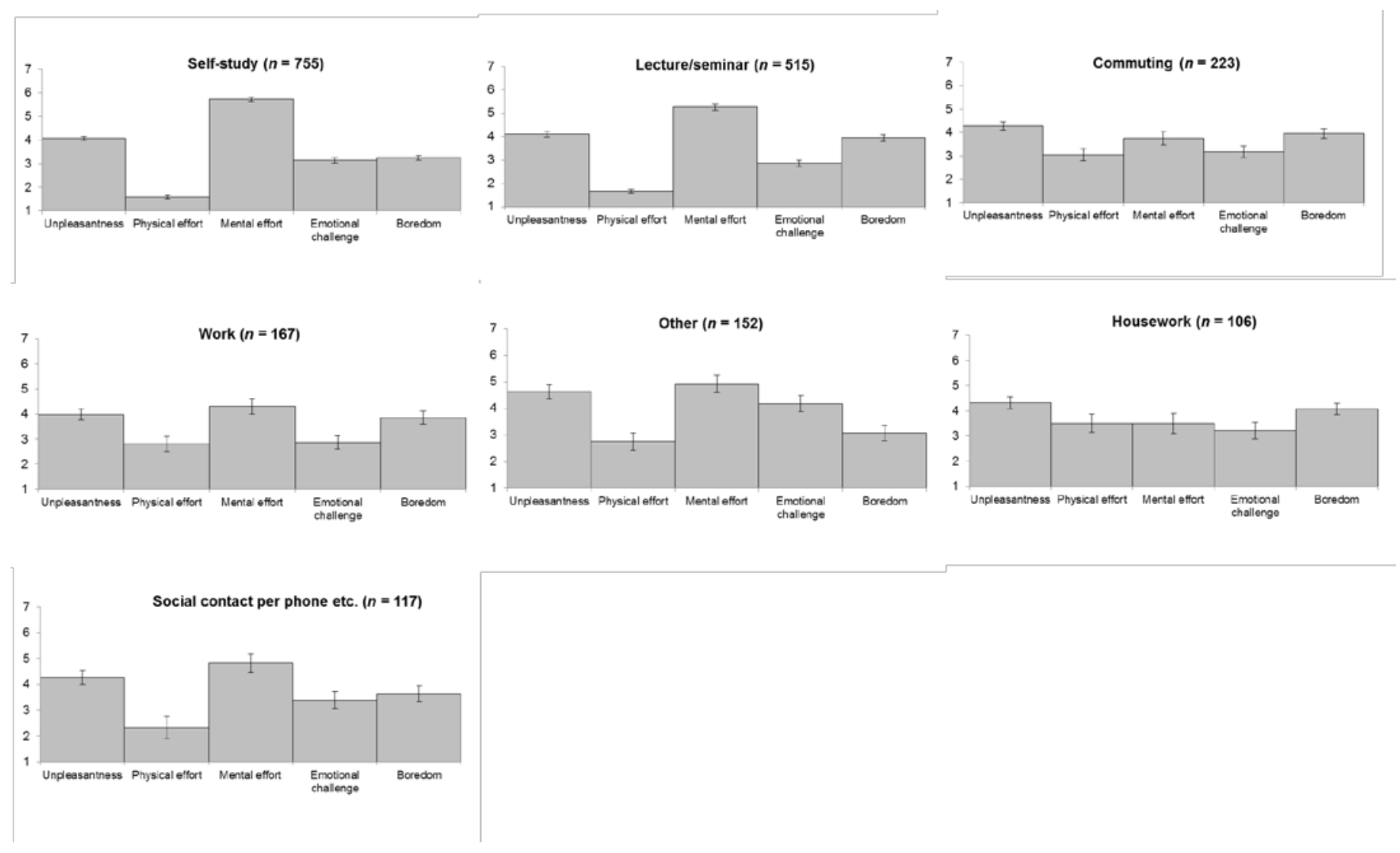

Figure 2. Means and 95\% CIs describing activity demands for activities that were reported in more than $10 \%$ of occasions (Main Study). 
$\%$ used during unpleasant/ challenging activity

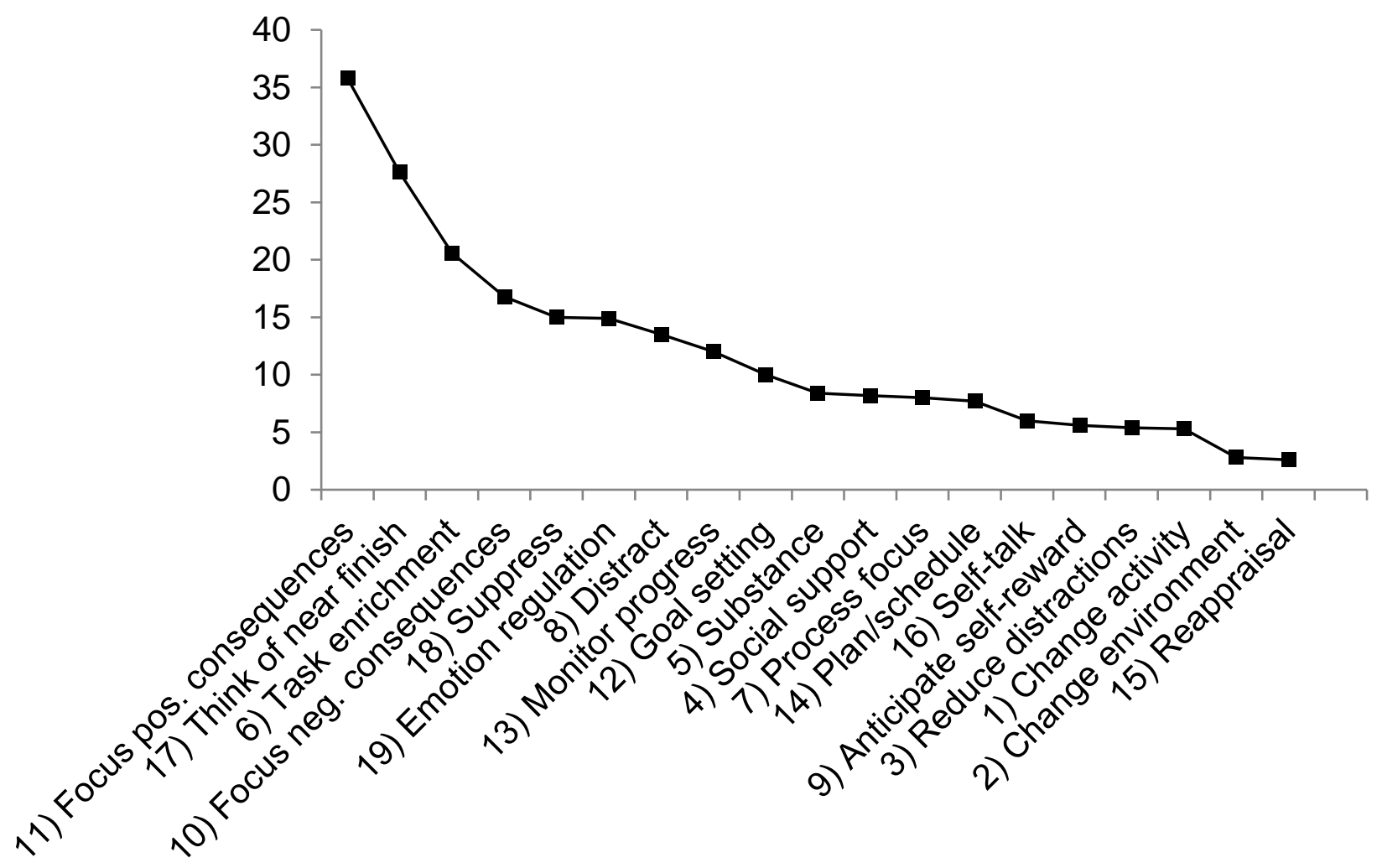

Figure 3. Proportions by which the 19 self-regulatory strategies were used when participants experienced an activity as unpleasant or challenging. There is missing data on strategy use for 9 out of 1940 occasions in which participants reported having performed an unpleasant or challenging activity, so 100\% equal 1931 occasions (Main Study). As participants could name more than one strategy at any given occasion, the sum of the relative frequencies exceeds $100 \%$. 
Predicted probability of using the strategy

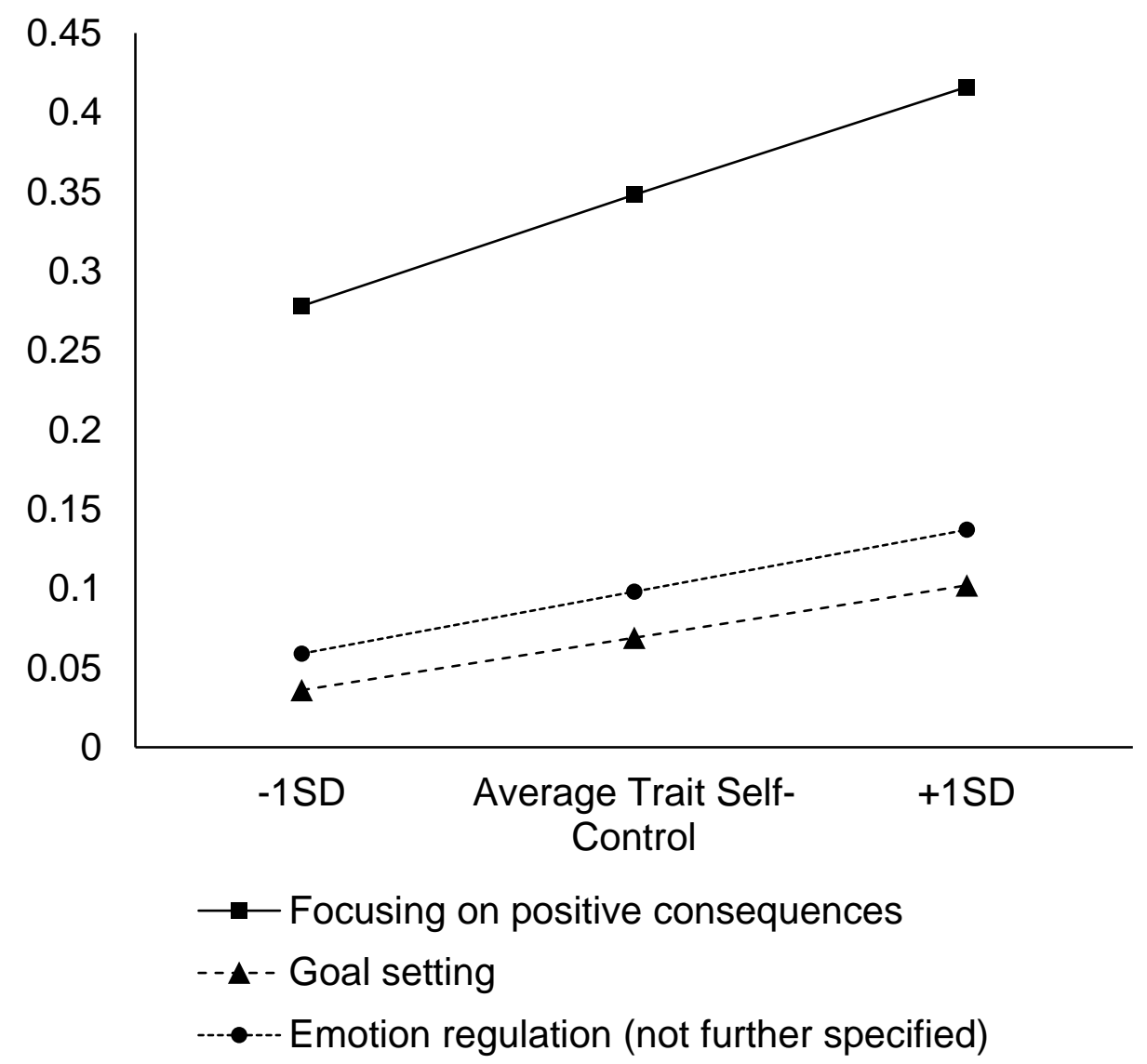

Figure 4. Predicted probabilities of using the strategies 11) Focusing on positive consequences, 12) Goal setting, and 19) Emotion regulation (not further specified) as a function of trait selfcontrol. Predicted log-odds from the logistic regression analyses were transformed into probabilities for ease of interpretation (Main Study). 


\section{Footnotes}

${ }^{1}$ To reflect the broad range of possible strategies that people may use to help themselves persist during unpleasant and challenging activities, we will from now on use the term "selfregulation" instead of "self-control” whenever we refer to processes (but will stick to "trait selfcontrol” for the individual difference construct). In the literature, "self-control” is often used in a more restricted sense as referring to the effortful suppression of impulses. While people may suppress the impulse to quit and thereby capitalize on their self-control, they may also use other self-regulatory strategies to help themselves persist, e.g., by making activities more fun. As we wish to include all kinds of strategies in our analysis, we will use the broader term "selfregulation” throughout the article, except when we refer to trait self-control.

${ }^{2}$ Note, that our coding system was designed in a way that would reduce conceptual overlap between strategies to a minimum and to make it easy to assign each coded strategy to one category only. Therefore, theoretical independence of the 19 strategies is highly likely. To nevertheless address empirically whether it would be possible to identify naturally occurring groupings of strategies into higher order factors, we submitted the strategies to factor analyses. The results of these exploratory factor analyses support our previous assumption of relative independence, because the groupings that emerged were not theoretically meaningful and difficult to interpret. More details on these factor analyses can be found in the SOM. Note, that low correlations between strategies within a “type” from Duckworth et al.’s (2016a) process model may occur if, for example, people do not tend to use multiple strategies from one type but rather prefer to diversify across types (e.g., use a situation modification strategy along with an additional reappraisal strategy). 
${ }^{3}$ In hindsight, we are aware that determining a study's sample size based on the sample sizes of previously published studies is problematic, given that, due to publication bias, consulting only published research may involve an overestimation of the true effect sizes.

${ }^{4}$ Demand types were chosen based on a pretest prior to the main study. We asked $N=425$ students during a Psychology lecture to fill in a brief survey that asked them first whether they had engaged in some unpleasant activity the day before. If so, we also asked them to indicate the extent to which the activity was physically effortful, mentally effortful, too easy/monotonous, meaningless/superfluous, caused anger/sadness/disgust or anxiety, or was boring. To investigate whether these demand types were exhaustive, we also asked participants to provide us with an explanation if the activity was unpleasant for a different reason. Only 18 out of the 256 (7\%) respondents who reported having engaged in an unpleasant activity the day before provided us with descriptions of such demands. These were in particular: "complicated," "my friends did not show up for the scheduled appointment, so I had to argue with them," "I was sick and therefore showering is not that pleasant!,” “effortful”, "getting up early after going out,” "tired”, “overcoming,”, “boring and effortful”, “time could have been used more meaningfully”, “no motivation”, “boring”, “bad weather $\rightarrow$ difficult external influences”, “unnecessary”, "because the system prevents a simple solution $\rightarrow$ didn’t know what’s going on”, “hangover”, “stress”, “boring, tiring”, “no motivation, didn’t feel like it.” Many of these additional demands appeared only once or twice, were in fact covered by our items (caused anger, mental effort, meaningless/superfluous, boring), or just provided descriptions that motivation was lacking but no indication of the specific demand. We therefore only included the additional item "frustrating" in the item pool of the main study as this appeared to be an additional demand type we had not yet covered. Note, that in the main study with 1940 instances at which participants reported a recent unpleasant activity, only at 63 instances they reported a different demand in their open 
response (3\%), some of which were again, in fact, redundant with the demand items. Hence, we believe that our item pool was relatively exhaustive. 
Supplemental Online Materials (SOM) for “Doing Despite Disliking: Self-Regulatory Strategies in Everyday Aversive Activities”

\section{Scenarios from Pilot Study 1}

“Exam” scenario. “Imagine the following scenario: You are preparing for a difficult exam. While you're reading for the exam you become increasingly bored. Not only is the textbook you have to memorize lengthy and the writing is bad, but you also don't really care for the subject. How do you keep yourself from putting away the textbook and how do you get yourself to keep going? Are there any strategies that you use? Such strategies may include changing what you think about, attending to certain aspects of the situation or ignoring other aspects, changing what you feel, or changing what you do or how you do it. What do you think about? What do you attend to? How do you change your feelings? How do you act? In general: How do you get yourself to keep going? In your response, please be as specific as possible. For example, let us know what it is you think about and not just that you think about something else. Let us know how you change your feelings and not just that you change them. Please list up to 10 strategies that you use to help yourself to continue studying even if you experience it as highly unpleasant.”

“Treadmill” scenario. "Imagine the following scenario: You are on a treadmill, exercising vigorously, and you are experiencing it as highly unpleasant and effortful: How do you keep yourself from stopping and keep yourself going? Are there any strategies that you use? Such strategies may include changing what you think about, attending to certain aspects of the situation or ignoring other aspects, changing what you feel, or changing what you do or how you do it. What do you think about? What do you attend to? How do you change your feelings? How do you act? In general: How do you get yourself to keep going? In your response, please be as 
specific as possible. For example, let us know what it is you think about and not just that you think about something else. Let us know how you change your feelings and not just that you change them. Please list up to 10 strategies that you use to help yourself to stay on the treadmill even if you experience it as highly unpleasant.”

Idiosyncratic scenario. "We are interested in your goals and the way you pursue them. What is a rather frequent activity in your life that - you need to engage in to achieve a goal that you consider important - but that you do not enjoy at all?

Please think of such an activity and describe it here in a few words. The activity (e.g., exercising on a treadmill in the gym): What is the goal that you pursue with this activity? (e.g., stay healthy) If you are engaging in the activity "[activity]“, how do you keep yourself from stopping and keep yourself going? Are there any strategies that you use? Such strategies may include changing what you think about, attending to certain aspects of the situation or ignoring other aspects, changing what you feel, or changing what you do or how you do it. What do you think about? What do you attend to? How do you change your feelings? How do you act? In general: How do you get yourself to keep going? In your response, please be as specific as possible. For example, let us know what it is you think about and not just that you think about something else. Let us know how you change your feelings and not just that you change them. Please list up to 10 strategies that you use to help yourself to keep going even if you experience the activity "[activity]" as highly unpleasant.” 


\section{Table S1}

\section{Coding Scheme Developed in Pilot Study 1, Items from Pilot Study 2a, and Exemplary References to Related Constructs}

\begin{tabular}{|c|c|c|c|c|c|}
\hline Strategy & Description & Distinguish from & Example & $\begin{array}{l}\text { English item from } \\
\text { Pilot Study 2a }\end{array}$ & Related Constructs \\
\hline \multicolumn{6}{|c|}{ Situation modification strategies } \\
\hline $\begin{array}{l}\text { 1) Changing the activity } \\
\text { itself }\end{array}$ & $\begin{array}{l}\text { Changing the nature of the } \\
\text { activity itself or of how it is } \\
\text { performed (without adding } \\
\text { an incentive from the } \\
\text { outside) }\end{array}$ & $\begin{array}{l}\text { Change environment, } \\
\text { distracting oneself from } \\
\text { the activity, reappraisal, } \\
\text { task enrichment }\end{array}$ & $\begin{array}{l}\text { I sing the } \\
\text { information./I } \\
\text { run more } \\
\text { slowly. }\end{array}$ & $\begin{array}{l}\text { I change the activity } \\
\text { itself (e.g., run more } \\
\text { slowly on the } \\
\text { treadmill, take notes } \\
\text { during studying). }\end{array}$ & $\begin{array}{l}\text { Varying the procedure (Sanson, Weir, } \\
\text { Harpster, \& Morgan, 1999) }\end{array}$ \\
\hline $\begin{array}{l}\text { 2) Changing the } \\
\text { environment }\end{array}$ & $\begin{array}{l}\text { Changing the environment } \\
\text { in which the activity is } \\
\text { performed (unspecified } \\
\text { whether this results in a } \\
\text { fresh start, task enrichment, } \\
\text { distraction of attention, or } \\
\text { removal of distractions) }\end{array}$ & $\begin{array}{l}\text { Change activity, } \\
\text { distracting oneself from } \\
\text { the activity, task } \\
\text { enrichment, reduce } \\
\text { distractions }\end{array}$ & $\begin{array}{l}\text { I change the } \\
\text { scenery in } \\
\text { which I study. }\end{array}$ & $\begin{array}{l}\text { I change the } \\
\text { environment where I } \\
\text { perform the activity } \\
\text { (e.g., work from a } \\
\text { coffee shop, take a } \\
\text { new route when } \\
\text { running). }\end{array}$ & $\begin{array}{l}\text { Environmental control (Kuhl, 1984); } \\
\text { situation selection (Duckworth, Gendler, } \\
\text { \& Gross, 2016); Ent, Baumeister, \& Tice } \\
\text { (2015); Pintrich (2000); Zimmerman } \\
\text { (1990, 2000) }\end{array}$ \\
\hline 3) Reducing distractions & $\begin{array}{l}\text { Reducing or removing } \\
\text { distractors or temptations } \\
\text { from one's environment }\end{array}$ & Change environment & $\begin{array}{l}\text { I turn off the } \\
\text { TV./I don’t buy } \\
\text { candy. }\end{array}$ & $\begin{array}{l}\text { I reduce or remove } \\
\text { distractions and } \\
\text { temptations. }\end{array}$ & $\begin{array}{l}\text { Environmental control (Kuhl, 1984); } \\
\text { situation modification (Duckworth et al., } \\
\text { 2014; 2016a); Ent et al. (2015); Pintrich } \\
\text { (2000); Zimmerman }(1990,2000)\end{array}$ \\
\hline 4) Seeking social support & Using the support of others & & $\begin{array}{l}\text { I'll ask a friend } \\
\text { to study with } \\
\text { me. }\end{array}$ & $\begin{array}{l}\text { I draw on the social } \\
\text { support of others. }\end{array}$ & $\begin{array}{l}\text { Help seeking (Frese \& Zapf, 1994; } \\
\text { Hacker, 1985); Bolger, Zuckerman, \& } \\
\text { Kessler (2000); Cohen \& Wills (1985); } \\
\text { Feeney (2004); Girme, Overall, \& } \\
\text { Simpson, (2013); Pintrich (2000); } \\
\text { Sarason, Sarason, \& Pierce, (1990); } \\
\text { Zimmerman (1990, 2000) }\end{array}$ \\
\hline 5) Taking a substance & $\begin{array}{l}\text { Taking substances, drugs, } \\
\text { medication }\end{array}$ & & $\begin{array}{l}\text { I drink an } \\
\text { energy drink. }\end{array}$ & $\begin{array}{l}\text { I take a substance or } \\
\text { drug (e.g., coffee or } \\
\text { energy drinks). }\end{array}$ & $\begin{array}{l}\text { Babcock \& Byrne (2000); Franke et al. } \\
\text { (2011); Hall, Irwin, Bowman, } \\
\text { Frankenberger, \& Jewett (2005); } \\
\text { Kaloyanides, McCabe, Cranford \& Teter } \\
\text { (2007); Kopetz \& Orehek (2015) }\end{array}$ \\
\hline 6) Task enrichment & $\begin{array}{l}\text { Adding some kind of } \\
\text { (positive) stimulus input } \\
\text { outside of the activity (e.g., } \\
\text { music, TV, phone talk, }\end{array}$ & $\begin{array}{l}\text { Change activity, change } \\
\text { environment, distracting } \\
\text { oneself from the activity, } \\
\text { reappraisal }\end{array}$ & $\begin{array}{l}\text { I play music } \\
\text { while I'm on } \\
\text { the treadmill. }\end{array}$ & $\begin{array}{l}\text { I add something } \\
\text { positive to the activity } \\
\text { to make it more } \\
\text { pleasant (e.g., listen }\end{array}$ & $\begin{array}{l}\text { Task embellishment (Butler, 1998); } \\
\text { temptation bundling (Milkman, Minson, } \\
\text { \& Volpp, 2013); adding intrinsic } \\
\text { incentives (Woolley \& Fishbach, 2015) }\end{array}$ \\
\hline
\end{tabular}


food, drink) without

to music, watch TV

changing the activity itself

while doing it).

\section{Attentional deployment strategies}

7) Adopting a process focus

8) Distracting oneself from the activity
Focusing one's attention on how the activity is performed

Focusing one's attention on something else outside of the activity (without

changing the activity itself or enriching the task by adding an outside incentive)
Change activity, change environment, reappraisal, task enrichment
I focus on the activity itself.

I count to ten while I'm running.
I focus my attention on the activity itself and on the way I am performing it.

I distract my attention by focusing on something else outside of the activity.
Process focus (Freund \& Hennecke, 2012, 2015); experiential focus (Fishbach \& Choi, 2012)

Distraction (Mischel, Ebbesen, \& Raskoff-Zeiss, 1972; Peake, Hebl, \& Mischel, 2002); attention control (Kuhl,

1984); attentional deployment

(Duckworth et al., 2016)

\section{Cognitive change strategies}

9) Anticipating selfreward

Adding a reward that is external to the activity or its goa

10) Focusing on negative consequences

11) Focusing on positive consequences

12) Goal setting
Thinking of negative consequences from nonpursuit of the activity, the prevention/avoidance goals that motivated the activity: Responses usually include negation (not being healthy), reference to negative outcome or reference to avoidance or prevention

Thinking of positive consequences from pursui of the activity, the promotion/approach goals that motivated the activity: Responses usually include reference to a desirable outcome

Committing to subgoals
I reward myself for each

successful week.

Focus on consequences, focus on positive consequences

I think about how I am going to get fat otherwise.

I do not want to fail the test.

I want to avoid illness.

Focus on consequences, thinking of the near finish, focus on negative

consequences how much better I will look.

I want to lose weight.

Planning/ scheduling
I set a goal that I have to meet.
I remind myself why I perform the activity and think of its

positive

consequences.

I define a specific goal or set subgoals for myself.
Bandura (1976); Goldfried \& Merbaum (1973); Grunschel, Schwinger, Steinmayr, \& Fries (2016)

Motivation control (Kuhl, 1984); outcome focus (Freund \& Hennecke, 2012, 2015); focus on instrumentality (Fishbach \& Choi, 2012); reasoning (Butler, 1998); high-level construal (Fujita, Trope, Liberman, \& Levin-Sagi, 2006)

Motivation control (Kuhl, 1984); outcome focus (Fishbach \& Choi, 2012; Freund \& Hennecke, 2012, 2015); reasoning (Butler, 1998); high-level construal (Fujita et al., 2006); indulgence in fantasies (Oettingen, Pak, \& Schnetter, 2001)

Goal setting (Locke \& Latham, 2002 2006); Klein, Wesson, Hollenbeck, Alge 
13) Monitoring one's goal Checking one’s progress progress

14) Planning/ scheduling

15) Reappraisal

16) Self-talk

17) Thinking of the near finish
Making a schedule or plan (may include the setting of subgoals, but only when timing is also set)

Thinking differently of the activity or changing its meaning (without changing the activity itself)

Motivating self-talk

Thinking about (nearby) task completion (not about the long-term goals)
Goal setting

Focus on consequences, change activity, emotion regulation (not further specified), focus on negative consequences, focus on positive consequences

Focus on consequences, focus on negative consequences, focus on positive consequences, reappraisal
I tell myself to be a warrior.

I look at how much money

I've saved

already./I use a fitbit to see how I'm doing.

I make a schedule and stick to it.

I imagine myself running in a race.

I think about how I will feel when I am done.
I check my goal progress. Bandura, \& Martinez-Pons (1992)

Carver \& Scheier (1982); Frese \& Zapf (1994); Dunlosky, Kubat-Silam, \& Hertzog (2003); Hacker (1985); Harkin et al. (2016); Kanfer \& Ackerman (1989); Pintrich (2000); Zimmerman (1990, 2000)

I make a plan or set a Implementation intentions (Gollwitzer, specific time for 1999); action planning (Sniehotta, engaging in the Scholz, \& Schwarzer, 2005) activity.

I think differently about the activity or change its meaning (e.g., imagine running in a race).

I talk to myself to motivate me.

Hardy, Hall \& Alexander (2001)

Hatzigeorgiadis, Zourbanos, Galanis, \& Theodorakis (2011)

I remind myself that soon I will be done with the activity.
Metcalfe \& Mischel (1999); Gross (1998a, 1998b); Gross \& John (2003); cognitive change (Duckworth et al. 2016a)

\section{Response modulation strategy}

18) Suppressing the

impulse to quit
Inhibiting the impulse to

quit
I force myself

to continue./I

just push

through it.
I suppress the impulse

to quit.

Response modulation (Duckworth et al., 2016a); inhibitory executive function (Diamond, 2013; Inzlicht, Berkman, \& Elkins-Brown, 2016); self-control (Baumeister, Bratslavsky, Muraven \& Tice, 1998)

\section{Not further specified strategy}

19) Emotion regulation (not further specified)
Regulating one's feelings (unspecified how this is done)
Focus on positive

consequences, reappraisal
I change my feelings. change how I feel (e.g., try to stay in a good mood).
Emotion regulation (e.g. Gross, 1998a

1998b); emotion control (Kuhl, 1984); Kanfer \& Ackerman (1989) 


\section{Details of the Exploratory Factor Analyses Conducted on the Data of Studies 2a and 2b}

As described in Footnote 2 of the article, we submitted the frequency ratings across the 19 strategies to exploratory factor analyses (principal axis analyses with varimax rotation, eigenvalue criterion). In Study 2a, five factors emerged. Six theoretically quite distinct strategies had their highest loadings on the first factor, namely adopting a process focus, emotion regulation (not further specified), reducing distractions, changing the activity itself, changing the environment, and reappraisal. Four of these highest loadings were in the range of only .40 to .50. The second factor was more straightforward to interpret theoretically: Goal setting, planning/scheduling, monitoring goal progress, and anticipating self-reward had their highest loadings (.44 to .66) on this factor, which we interpret as a factor describing goal-related strategies of cognitive change. The third, fourth, and fifth factors were, again, comprised of very diverse strategies and difficult to theoretically interpret: Thinking of the positive consequences, thinking of the near finish, thinking of the negative consequences, and suppression all loaded highest on the third factor; task enrichment, distracting oneself and taking a substance loaded highest on the fourth factor; self-talk and social support loaded highest on the fifth factor. In addition, six strategies had cross-loadings $\geq .30$ on other factors, indicating the absence of simple structure.

The results from the factor analysis of the frequency data from Pilot Study $2 b$ was not any clearer: It resulted in seven factors that were different from the factors of Study 2a. In addition, four strategies had cross-loadings $\geq .30$ and two strategies had no loadings $\geq .30$ on any factor. To our knowledge, no existing theoretical framework would fully support the groupings derived from either of these factor analyses. The diversity found in the strategies that we would have to assign to these factors supports our assumption that the strategies are theoretically relatively distinct. 
Table S2

Descriptive Statistics, Reliabilities, and Intercorrelations for Measures of Activity Demands (Main Study)

\begin{tabular}{|c|c|c|c|c|c|c|c|c|c|c|c|}
\hline Variable & $M$ & $S D$ & $\alpha$ & 2 & 3 & $3 a$ & $3 b$ & $3 c$ & 4 & $4 a$ & $4 b$ \\
\hline 1. Physical challenge & 2.22 & 1.81 & & -.21 & -.08 & -.03 & -.05 & -.13 & .04 & .11 & -.04 \\
\hline 2. Mental challenge & 4.95 & 1.85 & & & -.31 & -.35 & -.14 & -.27 & .20 & .15 & .21 \\
\hline 3. Boredom & 3.53 & 1.64 & .77 & & & .85 & .74 & .88 & .06 & -.03 & .14 \\
\hline 3а. Too easy/monotonous & 3.55 & 2.00 & & & & & .40 & .69 & .20 & -.12 & -.03 \\
\hline 3b. Meaningless/superfluous & 2.89 & 1.85 & & & & & & .48 & .26 & .17 & .28 \\
\hline 3c. Boring & 4.14 & 2.10 & & & & & & & -.01 & -.12 & .11 \\
\hline 4. Emotional challenge & 3.15 & 1.74 & .69 & & & & & & & .87 & .87 \\
\hline $\begin{array}{l}\text { 4a. Caused anger, sadness, } \\
\text { disgust, or anxiety }\end{array}$ & 2.63 & 2.00 & & & & & & & & & .87 \\
\hline 4b. Frustrating & 3.67 & 1.99 & & & & & & & & & \\
\hline
\end{tabular}

Note. Correlations across all measurement occasions. Significant correlation coefficients are written in bold. All correlations coefficients larger than $|.04|$ are significant at $p<.05$, all larger than $|.05|$ are significant at $p<.01$, all larger than $|.07|$ are significant at $p<.001$ 


\section{Table S3}

Results from Multilevel Regression Models of Perceived Self-Regulatory Success on Demands, Use of the Strategy Task Enrichment, and Interactions of Demands and Use of the Strategy 6) Task Enrichment

\begin{tabular}{lrrr}
\hline & \multicolumn{3}{c}{ Perceived self-regulatory success } \\
\cline { 2 - 4 } Predictor & \multicolumn{1}{c}{$B$} & $95 \%$ CI & \multicolumn{1}{c}{$p$} \\
\hline Intercept & 5.14 & {$[5.02,5.26]$} & $<.001$ \\
Task enrichment & 0.01 & {$[-0.15,0.18]$} & .865 \\
Physical effort & 0.12 & {$[-0.07,0.17]$} & $<.001$ \\
Mental effort & 0.03 & {$[-0.03,0.08]$} & .274 \\
Emotional challenge & -0.27 & {$[-0.33,-0.22]$} & $<.001$ \\
Boredom & -0.20 & {$[-0.25,-0.14]$} & $<.001$ \\
Physical effort $\times$ Task enrichment & 0.01 & {$[-0.09,0.12]$} & .836 \\
Mental effort $\times$ Task enrichment & -0.04 & {$[-0.15,0.07]$} & .511 \\
Emotional challenge $\times$ Task enrichment & -0.08 & {$[-0.21,0.04]$} & .178 \\
Boredom $\times$ Task enrichment & 0.14 & {$[0.02,0.27]$} & .029 \\
\hline
\end{tabular}

Note. Predictors were group-mean centered.

\section{Table S4}

Results from Multilevel Regression Models of Perceived Self-Regulatory Success on Demands, Use of the Strategy Distracting Oneself from the Activity, and Interactions of Demands and Use of the Strategy 8) Distracting Oneself from the Activity

\begin{tabular}{lrrr}
\hline & \multicolumn{3}{c}{ Perceived self-regulatory success } \\
\cline { 2 - 4 } Predictor & \multicolumn{1}{c}{ B5\% CI } & \multicolumn{1}{c}{$p$} \\
\hline Intercept & 5.23 & {$[5.12,5.35]$} & $<.001$ \\
Distracting oneself from the activity & -0.54 & {$[-0.75,-0.33]$} & $<.001$ \\
Physical effort & 0.11 & {$[0.06,0.15]$} & $<.001$ \\
Mental effort & 0.02 & {$[-0.02,0.07]$} & .325 \\
Emotional challenge & -0.31 & {$[-0.36,-0.26]$} & $<.001$ \\
Boredom & -0.12 & {$[-0.18,-0.07]$} & $<.001$ \\
Physical effort $\times$ Distracting oneself from the & 0.15 & {$[0.02,0.28]$} & .026 \\
activity & & & \\
Mental effort $\times$ Distracting oneself from the & -0.08 & {$[-0.21,0.04]$} & .193 \\
activity & & & \\
Emotional challenge $\times$ Distracting oneself from & 0.14 & {$[0.09,0.28]$} & .038 \\
the activity & & & \\
Boredom $\times$ Distracting oneself from the activity & -0.06 & {$[-0.20,0.09]$} & .464 \\
\hline
\end{tabular}

Note. Predictors were group-mean centered. 


\section{Table S5}

Results from Multilevel Regression Models of Perceived Self-Regulatory Success on Demands, Use of the Strategy Focusing on Negative Consequences, and Interactions of Demands and Use of the Strategy 10) Focusing on Negative Consequences

\begin{tabular}{lccr}
\hline & \multicolumn{3}{c}{ Perceived self-regulatory success } \\
\cline { 2 - 4 } Predictor & \multicolumn{1}{c}{ 95\% CI } & \multicolumn{1}{c}{$p$} \\
\hline Intercept & 5.13 & {$[5.01,5.25]$} & $<.001$ \\
Focusing on negative consequences & 0.15 & {$[-0.03,0.33]$} & .093 \\
Physical effort & 0.13 & {$[0.08,0.17]$} & $<.001$ \\
Mental effort & 0.02 & {$[-0.02,0.07]$} & .336 \\
$\begin{array}{l}\text { Emotional challenge } \\
\text { Boredom }\end{array}$ & -0.31 & {$[-0.36,-0.25]$} & $<.001$ \\
Physical effort $\times$ Focusing on negative & -0.17 & {$[-0.22,0.12]$} & $<.001$ \\
$\begin{array}{l}\text { consequences } \\
\text { Mental effort } \times \text { Focusing on negative }\end{array}$ & -0.03 & {$[-0.16,0.09]$} & .615 \\
$\begin{array}{l}\text { consequences } \\
\text { Emotional challenge } \times \text { Focusing on negative } \\
\text { consequences }\end{array}$ & -0.08 & {$[-0.21,0.05]$} & .254 \\
Boredom $\times$ Focusing on negative consequences & 0.11 & {$[-0.02 .0 .23]$} & .100 \\
\hline
\end{tabular}

Note. Predictors were group-mean centered.

Table S6

Results from Multilevel Regression Models of Perceived Self-Regulatory Success on Demands, Use of the Strategy Focusing on Positive Consequences, and Interactions of Demands and Use of the Strategy 11) Focusing on Positive Consequences

\begin{tabular}{lrcr}
\hline & \multicolumn{3}{c}{ Perceived self-regulatory success } \\
\cline { 2 - 4 } Predictor & \multicolumn{1}{c}{ 95\% CI } & \multicolumn{1}{c}{$p$} \\
\hline Intercept & 5.00 & {$[4.88,5 . .13]$} & $<.001$ \\
Focusing on positive consequences & 0.44 & {$[0.31,0.57]$} & $<.001$ \\
Physical effort & 0.18 & {$[0.12,0.23]$} & $<.001$ \\
Mental effort & 0.02 & {$[-0.03,0.08]$} & .422 \\
Emotional challenge & -0.30 & {$[-0.36,-0.24]$} & $<.001$ \\
Boredom & -0.15 & {$[-0.21,-0.09]$} & $<.001$ \\
$\begin{array}{l}\text { Physical effort } \times \text { Focusing on positive } \\
\text { consequences }\end{array}$ & -0.14 & {$[-0.23,-0.05]$} & .002 \\
$\begin{array}{l}\text { Mental effort } \times \text { Focusing on positive } \\
\text { consequences }\end{array}$ & -0.03 & {$[-0.13,0.07]$} & .557 \\
$\begin{array}{l}\text { Emotional challenge } \times \text { Focusing on positive } \\
\text { consequences }\end{array}$ & 0.07 & {$[-0.03,0.17]$} & .160 \\
Boredom $\times$ Focusing on positive consequences & -0.02 & {$[-0.12,0.09]$} & .780 \\
\hline
\end{tabular}

Note. Predictors were group-mean centered. 
Table S7

Results from Multilevel Regression Models of Perceived Self-Regulatory Success on Demands, Use of the Strategy Goal Setting, and Interactions of Demands and Use of the Strategy 12) Goal Setting

\begin{tabular}{lrrr}
\hline & \multicolumn{3}{c}{ Perceived self-regulatory success } \\
\cline { 2 - 4 } Predictor & \multicolumn{1}{c}{$B$} & $95 \%$ CI & \multicolumn{1}{c}{$p$} \\
\hline Intercept & 5.15 & {$[5.03,5.27]$} & $<.001$ \\
Goal setting & 0.08 & {$[-0.14,0.30]$} & .467 \\
Physical effort & 0.13 & {$[0.09,0.18]$} & $<.001$ \\
Mental effort & 0.02 & {$[-0.03,0.06]$} & .455 \\
Emotional challenge & -0.29 & {$[-0.34,0.24]$} & $<.001$ \\
Boredom & -0.16 & {$[-0.21,-0.11]$} & $<.001$ \\
Physical effort $\times$ Goal setting & -0.11 & {$[-0.26,0.04]$} & .163 \\
Mental effort $\times$ Goal setting & -0.06 & {$[-0.24,0.12]$} & .520 \\
Emotional challenge $\times$ Goal setting & 0.01 & {$[-0.16,0.19]$} & .874 \\
Boredom $\times$ Goal setting & -0.08 & {$[-0.27,0.10]$} & .379 \\
\hline
\end{tabular}

Note. Predictors were group-mean centered.

Table S8

Results from Multilevel Regression Models of Perceived Self-Regulatory Success on Demands, Use of the Strategy Monitoring one's Progress, and Interactions of Demands and Use of the Strategy 13) Monitoring one's Progress

\begin{tabular}{lrrr}
\hline & \multicolumn{3}{c}{ Perceived self-regulatory success } \\
\cline { 2 - 4 } Predictor & \multicolumn{1}{c}{ B } & $95 \% \mathrm{CI}$ & \multicolumn{1}{c}{$p$} \\
\hline Intercept & 5.13 & {$[5.01,5.24]$} & $<.001$ \\
Monitoring one's progress & 0.26 & {$[0.05,0.47]$} & .014 \\
Physical effort & 0.13 & {$[0.08,0.17]$} & $<.001$ \\
Mental effort & 0.01 & {$[-0.04,0.06]$} & .637 \\
Emotional challenge & -0.28 & {$[-0.33,-0.23]$} & $<.001$ \\
Boredom & -0.16 & {$[-0.21,-0.11]$} & $<.001$ \\
Physical effort $\times$ Monitoring one's progress & -0.04 & {$[-0.17,0.10]$} & .569 \\
Mental effort $\times$ Monitoring one’s progress & 0.00 & {$[-0.15,0.15]$} & .997 \\
Emotional challenge $\times$ Monitoring one's progress & -0.02 & {$[-0.18,0.13]$} & .786 \\
Boredom $\times$ Monitoring one's progress & -0.06 & {$[-0.23,0.11]$} & .464 \\
\hline
\end{tabular}

Note. Predictors were group-mean centered. 
Table S9

Results from Multilevel Regression Models of Perceived Self-Regulatory Success on Demands, Use of the Strategy Thinking of the Near Finish, and Interactions of Demands and Use of the Strategy 17) Thinking of the Near Finish

\begin{tabular}{lrrr}
\hline & \multicolumn{3}{c}{ Perceived self-regulatory success } \\
\cline { 2 - 4 } Predictor & \multicolumn{1}{c}{ 95\% CI } & \multicolumn{1}{c}{$p$} \\
\hline Intercept & 5.06 & {$[4.94,5.18]$} & $<.001$ \\
Thinking of the near finish & 0.34 & {$[0.19,0.48]$} & $<.001$ \\
Physical effort & 0.16 & {$[0.11,0.21]$} & $<.001$ \\
Mental effort & 0.03 & {$[-0.02,0.08]$} & .270 \\
Emotional challenge & -0.31 & {$[-0.37,-0.25]$} & $<.001$ \\
Boredom & -0.19 & {$[-0.25,-0.13]$} & $<.001$ \\
Physical effort $\times$ Thinking of the near finish & -0.15 & {$[-0.25,-0.06]$} & .002 \\
Mental effort $\times$ Thinking of the near finish & -0.08 & {$[-0.18,0.03]$} & .140 \\
Emotional challenge $\times$ Thinking of the near finish & 0.12 & {$[0.01,0.23]$} & .030 \\
Boredom $\times$ Thinking of the near finish & 0.04 & {$[-0.07,0.16]$} & .457 \\
\hline
\end{tabular}

Note. Predictors were group-mean centered.

Table S10

Results from Multilevel Regression Models of Perceived Self-Regulatory Success on Demands, Use of the Strategy Suppressing the Impulse to Quit, and Interactions of Demands and Use of the Strategy 18) Suppressing the Impulse to Quit

\begin{tabular}{lrrr}
\hline & \multicolumn{3}{c}{ Perceived self-regulatory success } \\
\cline { 2 - 4 } Predictor & \multicolumn{1}{c}{ S } & $95 \%$ CI & $p$ \\
\hline Intercept & 5.15 & {$[5.03,5.27]$} & $<.001$ \\
Supressing the impulse to quit & 0.06 & {$[-0.13,0.25]$} & .539 \\
Physical effort & 0.14 & {$[0.09,0.19]$} & $<.001$ \\
Mental effort & 0.02 & {$[-0.02,0.07]$} & .341 \\
Emotional challenge & -0.29 & {$[-0.34,-0.24]$} & $<.001$ \\
Boredom & -0.17 & {$[-0.22,-0.12]$} & $<.001$ \\
Physical effort $\times$ Suppressing the impulse to quit & -0.12 & {$[-0.24,0.00]$} & .050 \\
Mental effort $\times$ Suppressing the impulse to quit & -0.08 & {$[-0.22,0.06]$} & .262 \\
Emotional challenge $\times$ Suppressing the impulse to & 0.03 & {$[-0.11,0.16]$} & .698 \\
quit & & & \\
Boredom $\times$ Suppressing the impulse to quit & 0.02 & {$[-0.12,0.15]$} & .827 \\
\hline
\end{tabular}
Note. Predictors were group-mean centered. 


\section{Table S11}

Results from Multilevel Regression Models of Perceived Self-Regulatory Success on Demands, Use of the Strategy Emotion Regulation (Not Further Specified), and Interactions of Demands and Use of the Strategy 19) Emotion Regulation (Not Further Specified)

\begin{tabular}{lccr}
\hline & \multicolumn{3}{c}{ Perceived self-regulatory success } \\
\cline { 2 - 4 } Predictor & \multicolumn{1}{c}{ B } & $95 \%$ CI & $p$ \\
\hline Intercept & 5.11 & {$[4.99,5.23]$} & $<.001$ \\
Emotion regulation (not further specified) & 0.35 & {$[0.16,0.54]$} & $<.001$ \\
Physical effort & 0.13 & {$[0.09,0.18]$} & $<.001$ \\
Mental effort & 0.02 & {$[-0.03,0.07]$} & .385 \\
Emotional challenge & -0.28 & {$[-0.33,-0.23]$} & $<.001$ \\
Boredom & -0.17 & {$[-0.22,-0.12]$} & $<.001$ \\
Physical effort $\times$ Emotion regulation & -0.07 & {$[-0.19,0.04]$} & .245 \\
Mental effort $\times$ Emotion regulation & -0.05 & {$[-0.18,0.08]$} & .461 \\
Emotional challenge $\times$ Emotion regulation & -0.03 & {$[-0.16,0.10]$} & .646 \\
Boredom $\times$ Emotion regulation & 0.06 & {$[-0.08,0.20]$} & .420 \\
\hline
\end{tabular}

Note. Predictors were group-mean centered. 


\section{References}

Babcock, Q., \& Byrne, T. (2000). Student perceptions of methylphenidate abuse at a public liberal arts college. Journal of American College Health, 49, 143-145. doi: $10.1080 / 07448480009596296$

Bandura, A. (1976). Self-reinforcement: Theoretical and methodological considerations. Behaviorism, 4, 135-155.

Baumeister, R. F., Bratslavsky, E., Muraven, M., \& Tice, D. M. (1998). Ego depletion: Is the active self a limited resource? Journal of Personality and Social Psychology, 74, 12521265..

Bolger, N., Zuckerman, A., \& Kessler, R. C. (2000). Invisible support and adjustment to stress. Journal of Personality and Social Psychology, 79, 953-961. doi:10.1037/00223514.79.6.953

Butler, D. (1998). The strategic content learning approach to promoting self-regulated learning: A report of three studies. Journal of Educational Psychology, 90, 682-697. doi: 10.1037/0022-0663.90.4.682

Carver, C. S., \& Scheier, M. F. (1982). Control theory: A useful conceptual framework for personality-social, clinical, and health psychology. Psychological Bulletin, 92(1), 111-135. doi: 10.1037/0033-2909.92.1.111

Cohen, S., \& Wills, T. A. (1985). Stress, social support, and the buffering hypothesis. Psychological Bulletin, 98, 310-257. doi:10.1037/0033-2909.98.2.310

Diamond, A. (2013). Executive functions. Annual Review of Psychology, 64, 135-168. doi:10.1146/annurev-psych-113011-143750

Duckworth, A. L., Gendler, T. S., \& Gross, J. J. (2016a). Situational strategies for self-control. Perspectives on Psychological Science, 11, 35-55. doi:10.1177/1745691615623247 
Dunlosky, J., Kubat-Silam, A. K., \& Hertzog, C. (2003). Training monitoring skills improves older adults' self-paced associative learning. Psychology and Aging, 18, 340-345. doi:10.1037/0882-7974.18.2.340

Ent, M. R., Baumeister, R. F., \& Tice, D. M. (2015). Trait self-control and the avoidance of temptation. Personality and Individual Differences, 74, 12-15. doi: 10.1016/j.paid.2014.09.031

Feeney, B. C. (2004). A secure base: Responsive support of goal strivings and exploration in adult intimate relationships. Journal of Personality and Social Psychology, 87, 631-648. doi:10.1037/e633872013-126

Fishbach, A., \& Choi, J. (2012). When thinking about goals undermines goal pursuit. Organizational Behavior and Human Decision Processes, 118, 99-107. doi:10.1016/j.obhdp.2012.02.003

Franke, A. G., Bonertz, C., Christmann, M., Huss, M., Fellgiebel, A., Hildt, E., \& Lieb, K. (2011). Non-medical use of prescription stimulants and illicit use of stimulants for cognitive enhancement in pupils and students in Germany. Pharmacopsychiatry, 44, 60-66. doi: 10.1055/s-0030-1268417

Frese, M., \& Zapf, D. (1994). Action as the core of work psychology: A German approach. In H. C. Triandis, M. D. Dunnette, \& L. M. Hough (Eds.), Handbook of industrial and organizational psychology (Vol. 4, 2nd ed., pp. 271-340). Palo Alto, CA: Consulting Psychologists Press.

Freund, A. M., \& Hennecke, M. (2012). Changing eating behaviour vs. losing weight: The role of goal focus for weight loss in overweight women. Psychology and Health, 7, 25-42. doi:10.1080/08870446.2011.570867 
Freund, A. M., \& Hennecke, M. (2015). On means and ends: The role of goal focus in successful goal pursuit. Current Directions in Psychological Science, 24, 149-153. doi:10.1177/0963721414559774

Fujita, K., Trope, Y., Liberman, N., \& Levin-Sagi, M. (2006). Construal levels and self-control. Journal of Personality and Social Psychology, 90, 351-367. doi:10.1037/00223514.90.3.351

Girme, Y. U., Overall, N. C., \& Simpson, J. A. (2013). When visibility matters: Short-term versus long-term costs and benefits of visible and invisible support. Personality and Social Psychology Bulletin, 39, 1441-1454. doi:10.1177/0146167213497802

Goldfried, M. R., \& Merbaum, M. (1973). Behavior change through self-control. New York, NY: Holt, Rinehart and Winston.

Gollwitzer, P. M. (1999). Implementation intentions: Strong effects of simple plans. American Psychologist, 54, 493-503. doi:10.1037/0003-066X.54.7.493

Gross, J. J. (1998a). Antecedent-and response-focused emotion regulation: Divergent consequences for experience, expression, and physiology. Journal of Personality and Social Psychology, 74, 224-237. doi:10.1037/0022-3514.74.1.224

Gross, J. J. (1998b). The emerging field of emotion regulation: An integrative review. Review of General Psychology, 2, 271-299. doi:10.1037/1089-2680.2.3.271

Gross, J. J., \& John, O. P. (2003). Individual differences in two emotion regulation processes: Implications for affect, relationships, and well-being. Journal of Personality and social Psychology, 85, 348-362. doi:10.1037/0022-3514.85.2.348

Grunschel, C., Schwinger, M., Steinmayr, R., \& Fries, S. (2016). Effects of using motivational regulation strategies on students’ academic procrastination, academic performance, and 
well-being. Learning and Individual Differences, 49, 162-170.

doi:10.1016/j.lindif.2016.06.008

Hacker, W. (1985). Activity: A fruitful concept in industrial psychology. In M. Frese \& J. Sabini (Eds.), Goal directed behavior: The concept of action in psychology (pp. 262-284). Hillsdale, NJ: Erlbaum.

Hall, K. M., Irwin, M. M., Bowman, K. A., Frankenberger, W., \& Jewett, D. C. (2005). Illicit use of prescribed stimulant medication among college students. Journal of American College Health, 53, 167-174. doi: 10.3200/jach.53.4.167-174

Hardy, J., Hall, C. R., \& Alexander, M. R. (2001). Exploring self-talk and affective states in sport. Journal of Sports Sciences, 19, 469-475. doi: 10.1080/026404101750238926

Harkin, B., Webb, T. L., Chang, B. P., Prestwich, A., Conner, M., Kellar, I., ... \& Sheeran, P. (2016). Does monitoring goal progress promote goal attainment? A meta-analysis of the experimental evidence. Psychological Bulletin, 142, 198-229. doi:10.1037/bul0000025

Hatzigeorgiadis, A., Zourbanos, N., Galanis, E., \& Theodorakis, Y. (2011). Self-talk and sports performance: A meta-analysis. Perspectives on Psychological Science, 6, 348356.doi:10.1177/1745691611413136

Inzlicht, M., Berkman, E., \& Elkins-Brown, N. (2016). The neuroscience of “ego depletion” or: How the brain can help us understand why self-control seems limited. In E. HarmonJones \& M. Inzlicht (Eds.), Social Neuroscience: Biological Approaches to Social Psychology (pp. 101-123). New York, NY: Routledge.

Kaloyanides, K. B., McCabe, S. E., Cranford, J. A., \& Teter, C. J. (2007). Prevalence of illicit use and abuse of prescription stimulants, alcohol, and other drugs among college students: relationship with age at initiation of prescription stimulants. Pharmacotherapy: The 
Journal of Human Pharmacology and Drug Therapy, 27, 666-674. doi: 10.1592/phco.27.5.666

Kanfer, R., \& Ackerman, P. L. (1989). Motivation and cognitive abilities: An integrative/aptitude-treatment interaction approach to skill acquisition. Journal of Applied Psychology, 74, 657-690. doi: 10.1037/0021-9010.74.4.657

Klein, H. J., Wesson, M. J., Hollenbeck, J. R., \& Alge, B. J. (1999). Goal commitment and the goal-setting process: conceptual clarification and empirical synthesis. Journal of Applied Psychology, 84, 885-896. doi: 10.1037//0021-9010.84.6.885

Kopetz, C., \& Orehek, E. (2015). When the end justifies the means: Self-defeating behaviors as "rational” and "successful” self-regulation. Current Directions in Psychological Science, 24, 386-391. doi: 10.1177/0963721415589329

Kuhl, J. (1984). Volitional aspects of achievement motivation and learned helplessness: Toward a comprehensive theory of action control. Progress in Experimental Personality Research, 13, 99-171. doi:10.1016/b978-0-12-541413-5.50007-3

Locke, E. A., \& Latham, G. P. (2002). Building a practically useful theory of goal setting and task motivation: A 35-year odyssey. American Psychologist, 57, 705-717. doi:10.1037/0003-066X.57.9.705

Locke, E. A., \& Latham, G. P. (2006). New directions in goal-setting theory. Current Directions in Psychological Science, 15, 265-268. doi:10.1111/j.1467-8721.2006.00449.x

Metcalfe, J., \& Mischel, W. (1999). A hot/cool system analysis of delay of gratification: Dynamics of willpower. Psychological Review, 106, 3-19. doi:10.1037/0033-295x.106.1.3

Milkman, K. L., Minson, J. A., \& Volpp, K. G. (2013). Holding the Hunger Games hostage at the gym: An evaluation of temptation bundling. Management Science, 60, 283-299. doi:10.1287/mnsc.2013.1784 
Mischel, W., Ebbesen, E. B., \& Raskoff Zeiss, A. (1972). Cognitive and attentional mechanisms in delay of gratification. Journal of Personality and Social Psychology, 21, 204-218. doi:10.1037/h0032198

Oettingen, G., Pak, H. J., \& Schnetter, K. (2001). Self-regulation of goal-setting: Turning free fantasies about the future into binding goals. Journal of Personality and Social Psychology, 80, 736-753. doi:10.1037/0022-3514.80.5.736

Peake, P. K., Hebl, M., \& Mischel, W. (2002). Strategic attention deployment for delay of gratification in working and waiting situations. Developmental Psychology, 38, 313-326. doi:10.1037/0012-1649.38.2.313

Pintrich, P. R. (2000). The role of goal orientation in self-regulated learning. In M. Boekaerts, P. R. Pintrich, \& M. Zeidner (Eds.), Handbook of self-regulation (pp. 451-502). San Diego, CA: Academic Press. doi: 10.1016/B978-012109890-2/50043-3

Sansone, C., Weir, C., Harpster, L., \& Morgan, C. (1992). Once a boring task always a boring task? Interest as a self-regulatory mechanism. Journal of Personality and Social Psychology, 63, 379-390. doi:10.1037/0022-3514.63.3.379

Sarason, I. G., Sarason, B. R., \& Pierce, G. R. (1990). Social support: The search for theory. Journal of Social and Clinical Psychology, 9, 133-147. doi:10.1521/jscp.1990.9.1.133

Schunk, D. H. (1990). Goal setting and self-efficacy during self-regulated learning. Educational psychologist, 25, 71-86. doi: 10.1207/s15326985ep2501_6

Sniehotta, F. F., Scholz, U., \& Schwarzer, R. (2005). Bridging the intention-behaviour gap: Planning, self-efficacy, and action control in the adoption and maintenance of physical exercise. Psychology and Health, 20, 143-160. doi:10.1080/08870440512331317670 
Woolley, K., \& Fishbach, A. (2015). The experience matters more than you think: People value intrinsic incentives more inside than outside an activity. Journal of Personality and Social Psychology, 109, 968-982. doi:10.1037/pspa0000035

Zimmerman, B. J. (1990). Self-regulated learning and academic achievement: An overview. Educational Psychologist, 25, 3-17. doi: 10.1207/s15326985ep2501_2

Zimmerman, B. J. (2000). Attaining self-regulation: A social cognitive perspective. In M. Boekaerts, P. R. Pintrich, \& M. Zeidner (Eds.), Handbook of self-regulation (pp. 13-39). San Diego, CA: Academic Press. doi: 10.1016/B978-012109890-2/50031-7

Zimmerman, B. J., Bandura, A., \& Martinez-Pons, M. (1992). Self-motivation for academic attainment: The role of self-efficacy beliefs and personal goal setting. American Educational Research Journal, 29, 663-676. doi: 10.2307/1163261 